\title{
Laboratory Investigation of the
} Characterization of Cor-Tuf Flexural and Splitting Tensile Properties

M. Jason Roth, Todd S. Rushing, Omar G. Flores,

Devin K. Sham, and Jamie W. Stevens

US Army Corps of Engineers ${ }_{\circledast}$

Engineer Research and Development Center

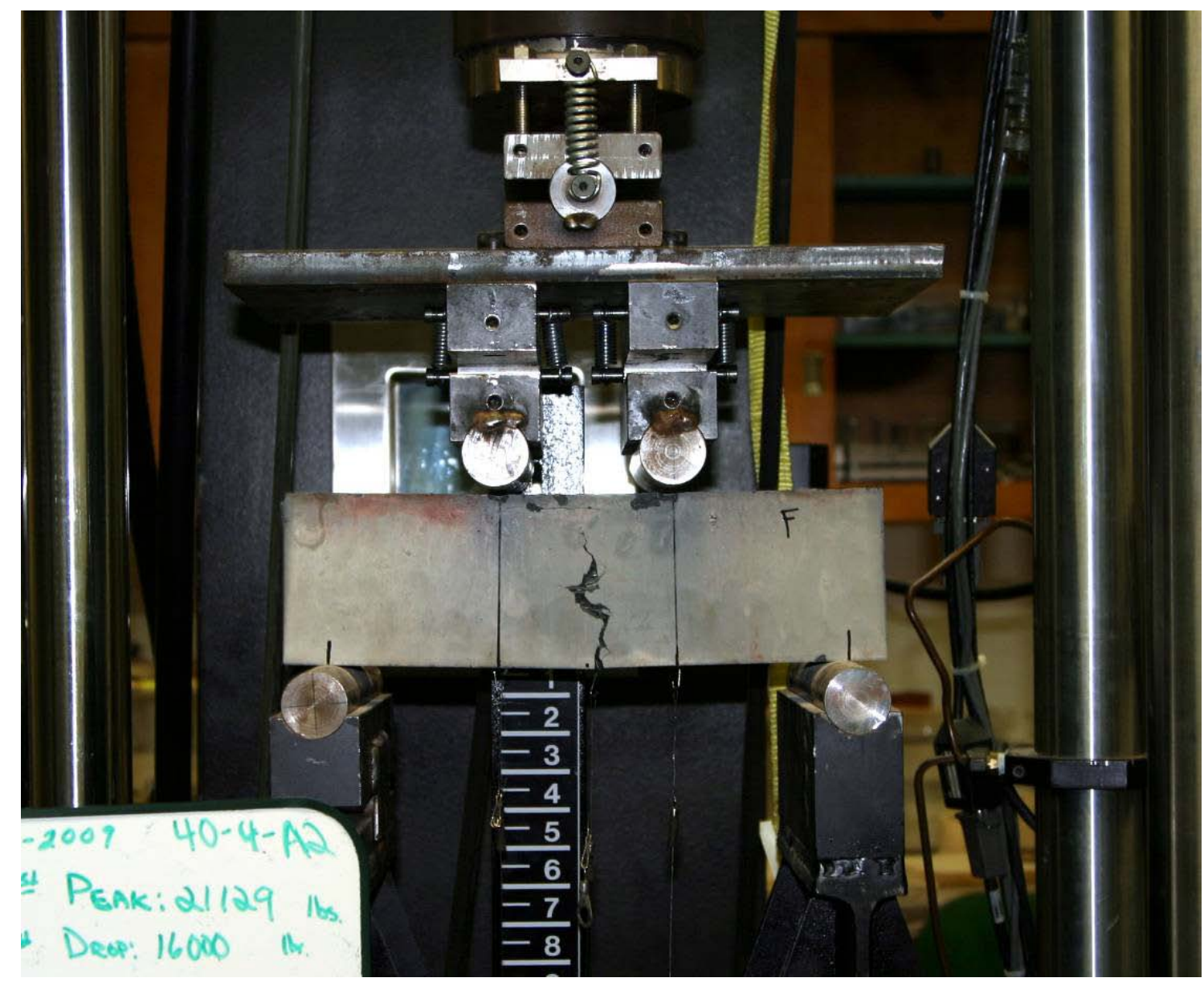




\section{Laboratory Investigation of the Characterization of Cor-Tuf Flexural and Splitting Tensile Properties}

M. Jason Roth, Todd S. Rushing, Omar G. Flores, Devin K. Sham, and Jamie W. Stevens

Geotechnical and Structures Laboratory

U.S. Army Engineer Research and Development Center 3909 Halls Ferry Road

Vicksburg, MS 39180-6199

Final report

Approved for public release; distribution is unlimited.

Prepared for Headquarters, U.S. Army Corps of Engineers

Washington, DC 20314-1000

Under ATO D.FP.2009.05/Defeat of Emerging Adaptive Threats Multi-scale Material Property Characterization Work Unit 


\begin{abstract}
Through multiple efforts, the U.S. Army Engineer Research and Development Center is conducting developmental research focused on new ultra high-performance cementitious materials. As a part of this research, a particular material, named Cor-Tuf, has been developed. Cor-Tuf is an ultra high-strength concrete, and has been shown to exhibit unconfined compressive strengths as high as $240 \mathrm{MPa}$. Randomly distributed steel reinforcement fibers (30-mm length) have been incorporated into Cor-Tuf to improve its ductility under tensile stresses, although their effect on performance has not been fully quantified. This considered, the research effort described herein was conducted to characterize the tension (splitting tensile) and flexural properties of the Cor-Tuf material. Seven experimental series were performed, and included 33 flexural tests and 12 splitting tensile tests. Testing was conducted utilizing reinforced and unreinforced material in order to directly quantify the fibers' influence on material response. This report provides descriptions of the experimental configurations, test specimens, and a summary of the experimental results.
\end{abstract}

DISCLAIMER: The contents of this report are not to be used for advertising, publication, or promotional purposes. Citation of trade names does not constitute an official endorsement or approval of the use of such commercial products. All product names and trademarks cited are the property of their respective owners. The findings of this report are not to be construed as an official Department of the Army position unless so designated by other authorized documents. 


\section{Contents}

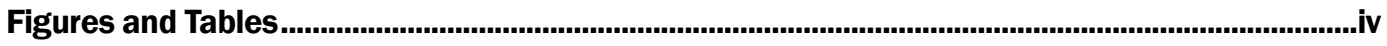

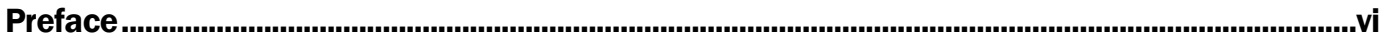

1 Introduction

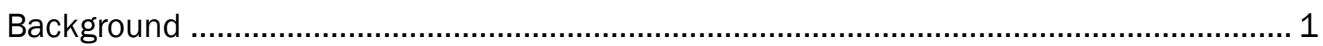

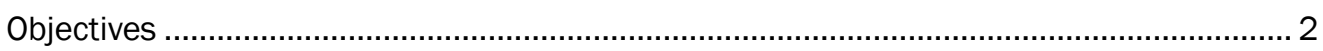

2 Experimental Program, Materials, and Procedures .......................................................... 4

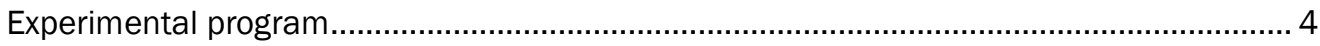

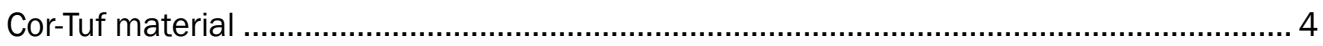

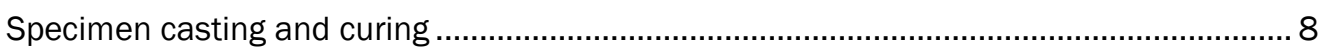

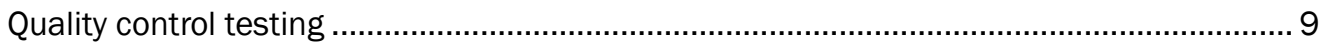

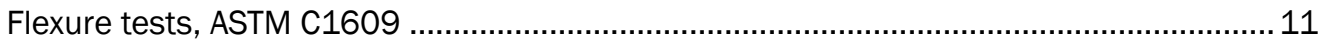

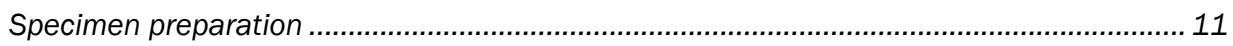

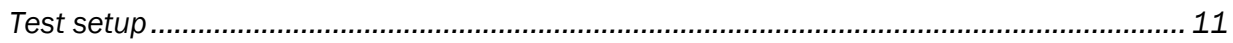

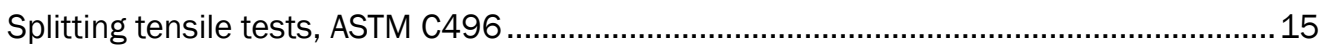

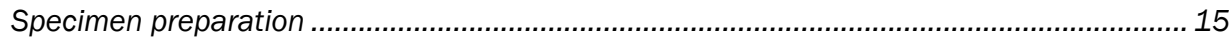

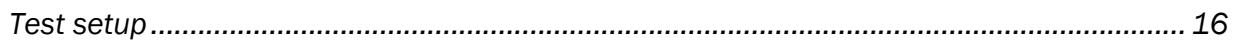

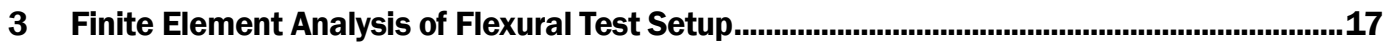

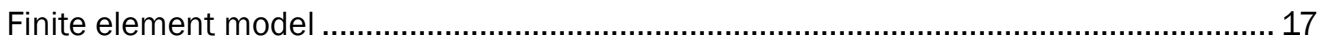

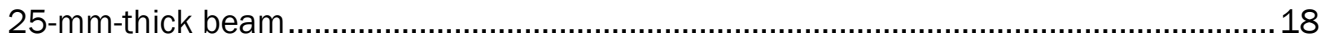

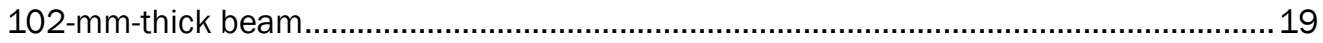

Maximum flexural stress, closed-form versus numerical solutions ..................................20

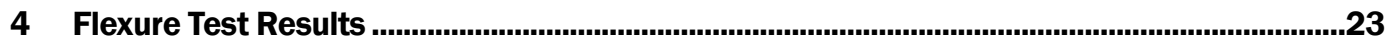

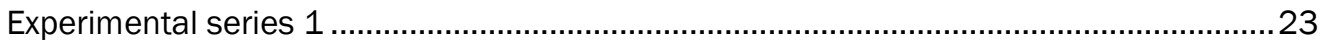

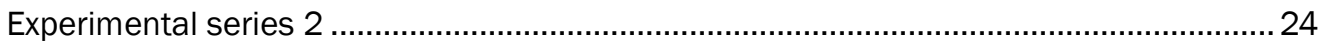

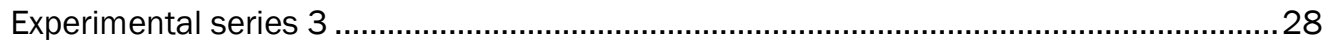

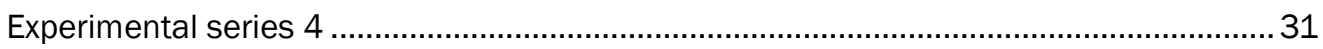

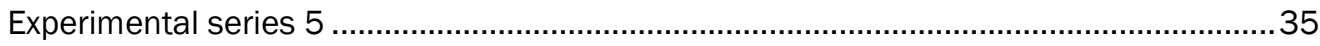

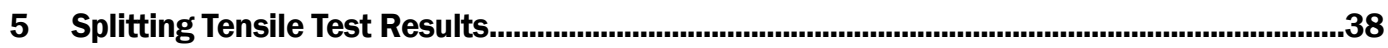

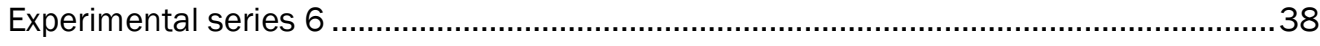

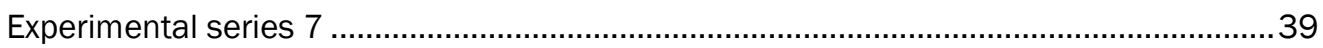

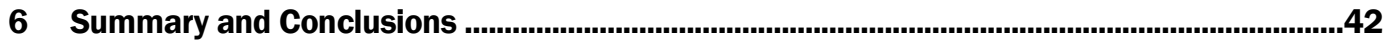

References ….................................................................................................................................................46

Appendix A: Beam Specimen Dimensions.................................................................................47

Report Documentation Page 


\section{Figures and Tables}

\section{Figures}

Figure 1. Dramix $®$ ZP305 hooked steel fibers. .......................................................................... 7

Figure 2. Beam and cube casting............................................................................................. 9

Figure 3. 1,016-mm-long beam with cut locations for 356-mm test specimens.............................. 12

Figure 4. Typical flexure test setup. ......................................................................................... 12

Figure 5. Four-point flexure steel plate control test...................................................................... 13

Figure 6. Steel plate control test, experimental data and closed-form solution. .............................. 14

Figure 7. Steel tube control test, experimental data and closed-form solution................................. 14

Figure 8. Discretized test sample with load and boundary conditions ..........................................18

Figure 9. FE results and closed-form solution for 25-mm-thick beam............................................ 19

Figure 10. FE results and closed-form solution for 102-mm-thick beam. ......................................20

Figure 11. FE calculated flexural stress in 25-mm beam ................................................................... 21

Figure 12. FE calculated flexural stress in 102-mm beam. ......................................................... 22

Figure 13. Load-displacement response, 25-mm beams without fibers. ....................................... 24

Figure 14. Series 1 failed flexural test specimens, 25-mm beams without fibers.......................... 25

Figure 15. Load-displacement response, 102-mm beams without fibers. .......................................2

Figure 16. Adjusted load-displacement response, 102-mm beams without fibers........................... 26

Figure 17. Failed flexural test specimens, 102-mm beams without fibers...................................... 27

Figure 18. Load-displacement response, 25-mm beams with fibers..............................................2

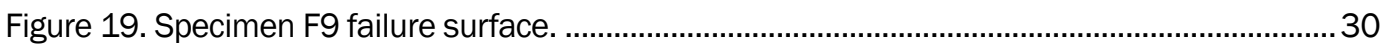

Figure 20. 25-mm beam load-displacement response, comparison of beams with and

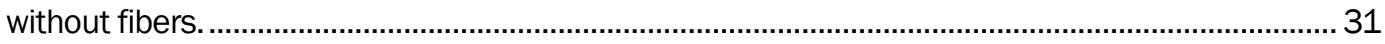

Figure 21. Failed flexural test specimens, 25-mm beams with fibers. ..........................................32

Figure 22. Load-displacement response, 102-mm beams with fibers............................................33

Figure 23. Specimen F15 failure surface. .......................................................................... 34

Figure 24. 102-mm beam load-displacement response, comparison of beams with and

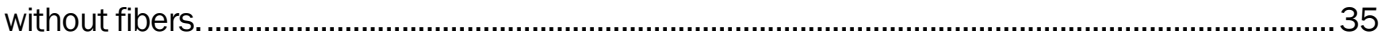

Figure 25. Failed flexural test specimens, 102-mm beams with fibers............................................36

Figure 26. Load-displacement response, 1,016-mm beams with fibers............................................36

Figure 27. Failed flexural test specimens, 102-mm beams with fibers. ........................................... 37

Figure 28. Splitting tensile response, fiber reinforced specimens..................................................39

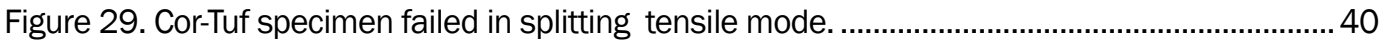

Figure 30. Splitting tensile response, unreinforced specimens. ....................................................... 40

Figure 31. Splitting tensile response, comparison of reinforced and unreinforced results. ............ 41 


\section{Tables}

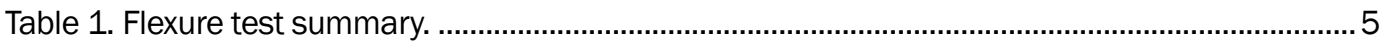

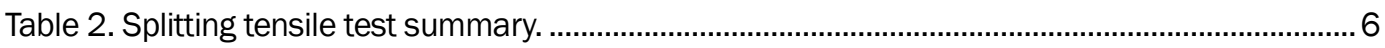

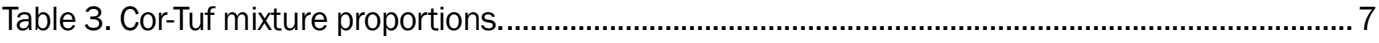

Table 4. Unconfined compression quality control test results. ….......................................................10

Table 5. Flexural tests, flexural strength summary..............................................................................43

Table 6. Flexural tests, Young's modulus summary. ………...........................................................4

Table 7. Splitting tensile tests, Splitting tensile strength summary...................................................45

Table A1. Beam specimen cross section dimensions, Series 1. ……………………………….......

Table A2. Beam specimen cross section dimensions, Series 2 ………………………………....4

Table A3. Beam specimen cross section dimensions, Series 3..........................................................48

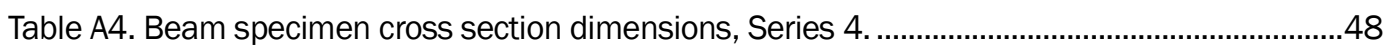

Table A5. Beam specimen cross section dimensions, Series 5 ........................................................49 


\section{Preface}

This report documents research conducted by personnel of the Survivability Engineering Branch (SvEB), Geosciences and Structures Division (GSD), and the Concrete and Materials Branch (CMB), Engineering Systems and Materials Division (ESMD), Geotechnical and Structures Laboratory (GSL), U.S. Army Engineer Research and Development Center (ERDC), Vicksburg, MS. The research was sponsored by Headquarters, U.S. Army Corps of Engineers, under Army Technology Objective D.FP.2009.05, “Defeat of Emerging Adaptive Threats" (DEFEAT). Work Package Manager for the DEFEAT program was M. J ason Roth, SvEB.

Principal investigators for this project were Roth and Dr. Todd S. Rushing, CMB. Omar G. Flores and Carey D. Price, SvEB, prepared the test specimens, and J amie W. Stevens, SvEB, assisted with preparation of the flexural test device. Test execution and data analysis were supported by Devin K. Sham, SvEB, Brett A. Williams, CMB, and Adilson Perez, University of Puerto Rico, Mayaguez. Perez also assisted with finite element analysis of the experimental setup. Instrumentation and testing support was provided by Dan Wilson, CMB, and George Cronia, ERDC Information Technology Laboratory. Emilee Booth, SvEB, assisted with report preparation.

This research was accomplished under the general supervision of J ames $\mathrm{L}$. Davis, Chief, SvEB; Bartley P. Durst, Chief, GSD; Dr. William P. Grogan, Deputy Director, GSL; and Dr. David W. Pittman, Director, GSL.

COL Gary E. J ohnston was Commander and Executive Director of ERDC. Dr. J effery P. Holland was Director. 


\section{Introduction}

\section{Background}

As a part of recent research efforts focused on the development of ultra high-strength, ultra high-performance cementitious materials, the U.S. Army Engineer Research and Development Center (ERDC), Geotechnical and Structures Laboratory (GSL), has developed a concrete material called Cor-Tuf. Cor-Tuf is an ultra high-strength concrete (unconfined compressive strength between $170 \mathrm{MPa}$ and $240 \mathrm{MPa}$ ), which is commonly reinforced with randomly distributed reinforcement fibers, such as the Dramix ${ }^{\circledR}$ ZP305 hooked steel fibers produced by Bekaert Corporation. A primary purpose for the development of Cor-Tuf was to establish a "standard" ultra high-strength concrete, which could be used as the basis for other research efforts, such as (1) numerical technique development for modeling of concrete response to blast and penetration effects, (2) development of further-enhanced ultra high-performance concretes, and (3) development of new blast and ballistic-resistant composites.

In consideration of Cor-Tuf's function as a baseline material for other research efforts, thorough characterization of its mechanical properties was required. In 2008, characterization of Cor-Tuf's mechanical properties and failure response under triaxial, uniaxial, and hydrostatic compressive loading was determined by the ERDC, Impacts and Explosive Effects Branch, and was reported in technical report ERDC/GSL TR-09-22 (Williams et al. 2009). With a primary focus on compressive response, the testing did not fully characterize the material's tensile or flexural properties. However, these data were required in order to quantify the effect of the reinforcement fibers and to fully characterize the material's response under tensile loading conditions.

Because of the need for characterization of the flexural, tensile, and fracture toughness properties of Cor-Tuf, a collaborative effort was initiated between ERDC and the University of Michigan, Ann Arbor to investigate these aspects of the material. Within the characterization program, laboratory experiments were conducted in seven areas, as follows: 
- Four-point beam flexure tests on Cor-Tuf material with steel fiber reinforcement

- Four-point beam flexure tests on Cor-Tuf material without steel fiber reinforcement

- Splitting tensile tests on Cor-Tuf material with steel fiber reinforcement

- Splitting tensile tests on Cor-Tuf material without steel fiber reinforcement

- Notched beam fracture-toughness tests on Cor-Tuf material without steel fiber reinforcement

- Direct tension tests on Cor-Tuf material with steel fiber reinforcement

- Single-fiber pull tests for single reinforcement fibers pulled from the Cor-Tuf matrix

With the exception of the single-fiber pull tests, all experimental efforts were conducted to characterize macroscale properties of the Cor-Tuf cementitious matrix and the fiber-reinforced Cor-Tuf material. The singlefiber pull tests were conducted to characterize the mesoscale ${ }^{1}$ interaction between a single fiber and the cementitious matrix, in support of micromechanical model development for Cor-Tuf.

As a part of the collaborative effort, ERDC personnel performed four-point beam flexure tests (with and without steel fibers) and splitting tensile tests (with and without steel fibers). University of Michigan investigators also performed four-point beam flexure tests and splitting tensile tests for material with steel fibers. The University of Michigan program also included notched beam fracture-toughness tests, direct tension tests, and single-fiber pull tests. A detailed report of the University of Michigan experimental results is not given here but will be documented as part of an independent report by the university.

\section{Objectives}

This report documents the results of seven experimental series conducted by ERDC to characterize the flexural and splitting tensile properties of CorTuf concrete with and without distributed steel fiber reinforcement. The objectives of these experiments were to determine relevant mechanical

\footnotetext{
1 In this case, mesoscale is defined as the explicit consideration of fibers within a homogeneous cementitious medium. This is in contrast to a macroscale view of the material, in which the fibers and cementitious material are considered as one homogeneous medium.
} 
properties of the material when exposed to the specified loading conditions, the results of which would be used as a baseline for further Cor-Tuf enhancement and as material response characteristics used in the development of new numerical models for ultra high-performance concrete. A description of the Cor-Tuf material, experimental procedures, and a summary of the test results are given herein. 


\section{Experimental Program, Materials, and Procedures}

\section{Experimental program}

The objective of the ERDC portion of this experimental program was to determine the flexural and splitting tensile characteristics of the Cor-Tuf material. As such, seven experimental series were conducted, which included multiple four-point beam flexure tests and splitting tensile tests. The beam flexure tests varied in terms of reinforcement conditions (with and without fiber reinforcement), beam depth (25-mm and 102-mm-deep beams were tested), and beam span (beam spans of 305-mm and 914-mm were used). The splitting tensile tests varied in terms of reinforcement conditions only (with and without reinforcement). A total of 33 flexure tests and 12 splitting tensile tests was conducted, summaries of which are given in Tables 1 and 2, respectively.

\section{Cor-Tuf material}

Cor-Tuf is the nomenclature given to a family of ultra high-performance concretes (UHPCs) developed at ERDC. UHPCs can be distinguished from other concrete materials, in part, by their high unconfined compressive strengths (ranging from 170 to $240 \mathrm{MPa}$ in the case of Cor-Tuf cylinder tests). Since the fresh and hardened properties of UHPCs can be very sensitive to slight changes in constitutive materials, the exact mixture proportion is often adjusted to achieve desired properties. For the experiments described herein, the material composition was based on the mixture proportion utilized in a prior ERDC study (Williams et al. 2009). However, it is noted that a subtle difference was required for the superplasticizer material. The superplasticizer used in the previous study, ADVA 170, was discontinued by the manufacturer (WR Grace). Therefore, its replacement product, ADVA 190, was used in the present study. Even with the minor change in superplasticizers, by utilizing a generally consistent material composition in both studies, the mechanical properties determined from each could be used conjunctively to describe material response under various loading conditions. 
Table 1. Flexure test summary.

\begin{tabular}{|c|c|c|c|c|}
\hline $\begin{array}{l}\text { Experimental } \\
\text { Series }\end{array}$ & Specimen No. & $\begin{array}{l}\text { Specimen Size }{ }^{1} \\
(\mathrm{I} \times \mathbf{w} \times \mathrm{h}), \mathrm{mm}\end{array}$ & $\begin{array}{l}\text { With or Without } \\
\text { Fibers }\end{array}$ & Batch No. ${ }^{2}$ \\
\hline \multirow{6}{*}{1} & NF-1 & $356 \times 102 \times 25$ & without fibers & 1 \\
\hline & NF-2 & $356 \times 102 \times 25$ & without fibers & 1 \\
\hline & NF-3 & $356 \times 102 \times 25$ & without fibers & 1 \\
\hline & NF-4 & $356 \times 102 \times 25$ & without fibers & 1 \\
\hline & NF-5 & $356 \times 102 \times 25$ & without fibers & 3 \\
\hline & NF-6 & $356 \times 102 \times 25$ & without fibers & 3 \\
\hline \multirow{6}{*}{2} & NF-7 & $356 \times 102 \times 102$ & without fibers & 1 \\
\hline & NF-8 & $356 \times 102 \times 102$ & without fibers & 1 \\
\hline & NF-9 & $356 \times 102 \times 102$ & without fibers & 1 \\
\hline & NF-10 & $356 \times 102 \times 102$ & without fibers & 1 \\
\hline & NF-11 & $356 \times 102 \times 102$ & without fibers & 1 \\
\hline & NF-12 & $356 \times 102 \times 102$ & without fibers & 1 \\
\hline \multirow{9}{*}{3} & F-1 & $356 \times 102 \times 25$ & with fibers & 2 \\
\hline & $\mathrm{F}-2$ & $356 \times 102 \times 25$ & with fibers & 2 \\
\hline & F-3 & $356 \times 102 \times 25$ & with fibers & 2 \\
\hline & $\mathrm{F}-4$ & $356 \times 102 \times 25$ & with fibers & 2 \\
\hline & $\mathrm{F}-5$ & $356 \times 102 \times 25$ & with fibers & 2 \\
\hline & F-6 & $356 \times 102 \times 25$ & with fibers & 2 \\
\hline & F-7 & $356 \times 102 \times 25$ & with fibers & 2 \\
\hline & F-8 & $356 \times 102 \times 25$ & with fibers & 2 \\
\hline & F-9 & $356 \times 102 \times 25$ & with fibers & 2 \\
\hline \multirow{6}{*}{4} & $\mathrm{~F}-10$ & $356 \times 102 \times 102$ & with fibers & 3 \\
\hline & F-11 & $356 \times 102 \times 102$ & with fibers & 3 \\
\hline & $\mathrm{F}-12$ & $356 \times 102 \times 102$ & with fibers & 3 \\
\hline & $\mathrm{F}-13$ & $356 \times 102 \times 102$ & with fibers & 3 \\
\hline & $\mathrm{F}-14$ & $356 \times 102 \times 102$ & with fibers & 3 \\
\hline & $\mathrm{F}-15$ & $356 \times 102 \times 102$ & with fibers & 3 \\
\hline \multirow{6}{*}{5} & $\mathrm{~F}-16$ & $1016 \times 102 \times 102$ & with fibers & 3 \\
\hline & $\mathrm{F}-17$ & $1016 \times 102 \times 102$ & with fibers & 3 \\
\hline & $\mathrm{F}-18$ & $1016 \times 102 \times 102$ & with fibers & 3 \\
\hline & $\mathrm{F}-19$ & $1016 \times 102 \times 102$ & with fibers & 4 \\
\hline & $\mathrm{F}-20$ & $1016 \times 102 \times 102$ & with fibers & 4 \\
\hline & $\mathrm{F}-21$ & $1016 \times 102 \times 102$ & with fibers & 4 \\
\hline \multicolumn{5}{|c|}{$\begin{array}{l}1 \text { Specimen sizes in Table } 1 \text { are nominal. Reference appendix A for exact specimen dimensions. } \\
2 \text { Refers to production batches used to cast test specimens. Reference Table } 4 \text { for unconfined } \\
\text { compression test results for each batch. }\end{array}$} \\
\hline
\end{tabular}


Table 2. Splitting tensile test summary.

\begin{tabular}{|l|l|l|l|l|}
\hline \multirow{4}{*}{$\begin{array}{l}\text { Experimental } \\
\text { Series }\end{array}$} & Specimen No. & $\begin{array}{l}\text { Specimen Size } \\
\text { (dia. } \times \text { length), } \\
\text { mm }\end{array}$ & $\begin{array}{l}\text { With or Without } \\
\text { Fibers }\end{array}$ & Batch No. ${ }^{1}$ \\
\hline \multirow{5}{*}{6} & $102 \times 204$ & with fibers & 5 \\
\cline { 2 - 5 } & ST-1 & $102 \times 204$ & with fibers & 5 \\
\cline { 2 - 5 } & ST-3 & $102 \times 204$ & with fibers & 5 \\
\cline { 2 - 5 } & ST-4 & $102 \times 204$ & with fibers & 5 \\
\cline { 2 - 5 } & ST-5 & $102 \times 204$ & with fibers & 5 \\
\cline { 2 - 5 } & ST-6 & $102 \times 204$ & with fibers & 5 \\
\hline & ST-7 & $102 \times 204$ & without fibers & 6 \\
\cline { 2 - 5 } & ST-8 & $102 \times 204$ & without fibers & 6 \\
\cline { 2 - 5 } & ST-9 & $102 \times 204$ & without fibers & 6 \\
\cline { 2 - 5 } & ST-10 & $102 \times 204$ & without fibers & 6 \\
\cline { 2 - 5 } & ST-11 & $102 \times 204$ & without fibers & 6 \\
\cline { 2 - 5 } & ST-12 & $102 \times 204$ & without fibers & 6 \\
\hline
\end{tabular}

Regarding particle size in the material, Cor-Tuf can be broadly characterized as a reactive powder concrete (RPC). RPCs are composed of fine aggregates and pozzolanic powders but do not include coarse aggregates, such as those found in conventional concrete. The maximum particle size in Cor-Tuf is limited to that of silica sand, a foundry grade Ottawa sand, which has a maximum size of approximately $0.6 \mathrm{~mm}$.

The mixture proportion for Cor-Tuf utilized in this study, as reported in Table 3, was designed to develop ultra high compressive strength, while maintaining workability and production economy. Constitutive materials utilized in the mixture were processed fine silica sand, finely ground quartz flour, Portland cement, and amorphous micro-silica (also known as silica fume). Additionally, a polycarboxylate type superplasticizer was included to decrease water demand, aid mixing, and improve workability. The water-tocement ratio was restricted to about 0.21 , which is far lower than values typical of conventional concrete. ${ }^{1}$

\footnotetext{
${ }^{1}$ Conventional concretes have a water-to-cement ratio near 0.40 .
} 
Table 3. Cor-Tuf mixture proportions.

\begin{tabular}{|c|c|c|c|c|c|c|c|}
\hline & $\begin{array}{l}\text { Class } \mathrm{H} \\
\text { Cement }\end{array}$ & $\begin{array}{l}\text { US Silica } \\
\text { F55 Sand }\end{array}$ & $\begin{array}{l}\text { Sil-co-Sil } \\
75 \text { Silica } \\
\text { Flour }\end{array}$ & $\begin{array}{l}\text { Elkem } \\
\text { ES900W } \\
\text { Silica Fume }\end{array}$ & $\begin{array}{l}\text { ADV } 190 \\
\text { Superplasticizer }{ }^{1}\end{array}$ & $\begin{array}{l}\text { Tap } \\
\text { Water }\end{array}$ & $\begin{array}{l}\text { Dramix® } \\
\text { ZP305 } \\
\text { Fibers } 2\end{array}$ \\
\hline Mix proportion (mass) & 1 & 0.9674 & 0.2768 & 0.3890 & $0.014 \pm 25 \%$ & 0.2082 & 0.3100 \\
\hline \multicolumn{8}{|c|}{$\begin{array}{l}{ }^{1} \text { The given superplasticizer proportion of } 0.014 \text { is estimated. Exact proportions varied ( } \pm 25 \text { percent) between } \\
\text { batches to achieve desired workability. }\end{array}$} \\
\hline
\end{tabular}

For test samples identified as containing steel fiber reinforcement, Dramix ${ }^{\circledR}$ ZP305 fibers were included at the mass fraction indicated in Table 3. This fiber loading ratio corresponded to a volumetric content of approximately 3.6\%, which was somewhat greater than the volume content normally recommended for typical fiber-reinforced concrete applications.

The manufacturer's product data sheet for the ZP305 fibers stated that they were approximately 30-mm long, had a diameter of approximately 0.55- $\mathrm{mm}$, and were hooked at each end. The tensile strength for the steel fibers was reported by the manufacturer to be $1100 \mathrm{MPa}$. The ZP305 fibers were adhered together in bundles with a water soluble adhesive when purchased and were introduced into the fresh concrete mixture after it reached a flowable pastelike consistency. During the mixing process, the fibers dispersed as the adhesive dissolved in the fresh concrete, ideally resulting in uniform distribution and random orientation within the cementitious matrix. A sample of the ZP305 fibers is shown in Figure 1.

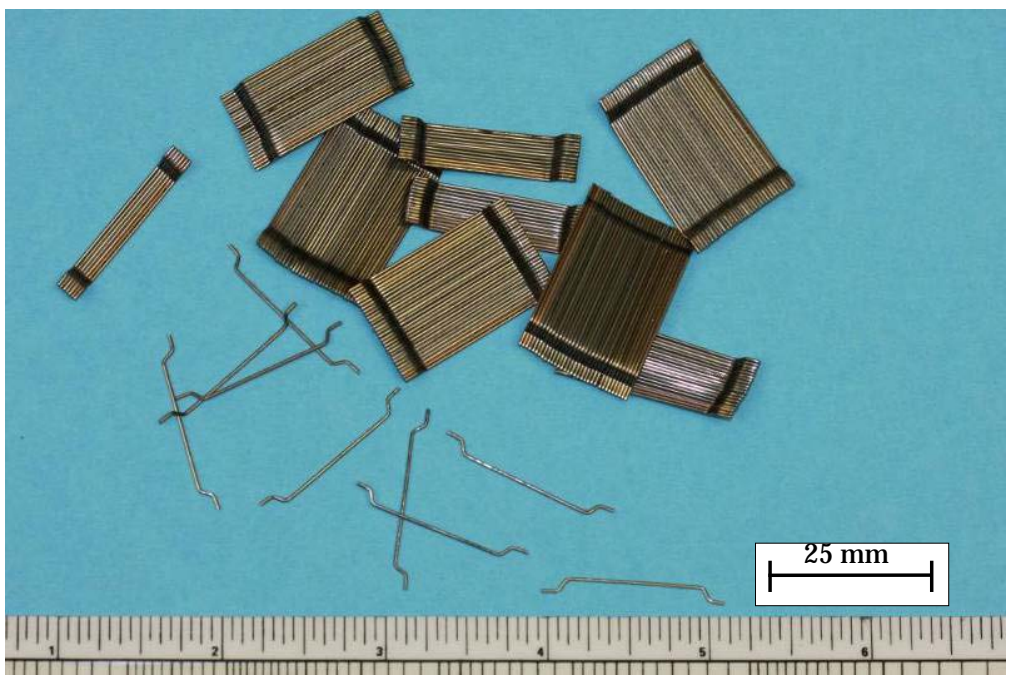

Figure 1. Dramix® ZP305 hooked steel fibers. 


\section{Specimen casting and curing}

The Cor-Tuf material for the 25-mm-deep beams was prepared in a Hobart $\mathrm{H}-600$ Commercial Mixer with a $0.06 \mathrm{~m}^{3}$ bowl. For optimal mixing and due to the loose nature of the four dry constituent materials, the batches were sized to yield about $0.02 \mathrm{~m}^{3}$, or about $33 \%$ of the mixer's capacity. This size assured that enough material was present to completely engage the mixing paddle, while not exceeding the torque limit of the mixer motor, nor having spillage of material during dry mixing.

The Cor-Tuf material for the 102-mm-deep beams was prepared in an Eirich R09 Intensive Mixer with a working capacity of $0.15 \mathrm{~m}^{3}$. For optimal mixing, the batches were sized to yield about $0.06 \mathrm{~m}^{3}$, or about $40 \%$ of the mixer's capacity. Similar to the Hobart mixer, this size assured that enough material was present to completely engage the mixing paddles, while not exceeding the torque limit of the mixer motors.

The four dry constituent materials were pre-weighed, loaded into the mixing bowl by hand, and dry-blended for $5 \mathrm{~min}$. The water and superplasticizer were pre-weighed and combined before being gradually added to the dry mixture, while actively mixing. Mixing time was approximately 15 min to achieve a wetted, flowable paste. For specimens with fiber reinforcement, a preweighed amount of steel fibers was added by hand to the mixer under shear, and the concrete was then allowed to mix for about 10 more min. For specimens without fiber reinforcement, the concrete was mixed for about $10 \mathrm{~min}$ beyond the paste condition, so that the two preparations received equivalent total mixing times.

After mixing, the fresh material was placed into beam molds and cylinders for the flexure and splitting tensile tests, respectively. The beam molds were fabricated at ERDC using 19-mm-thick plastic-coated plywood, and the splitting tensile test specimens were cast in commercially available plastic cylinders. To prevent unwanted entrapment of air within the specimens, the fresh material was placed in increments of thirds in the molds. During placement, the molds were placed on a vibratory table, which assisted with the even spread and consolidation of the fresh concrete. To assist in demolding of the flexure samples, prior to casting, the mold faces were sprayed with a light coat of WD- 40 for use as a release agent. Casting of a 356- $\mathrm{mm} \times 102-\mathrm{mm} \times 25-\mathrm{mm}$ beam and a 51-mm cube specimen (for unconfined compression testing) is shown in Figure 2. 


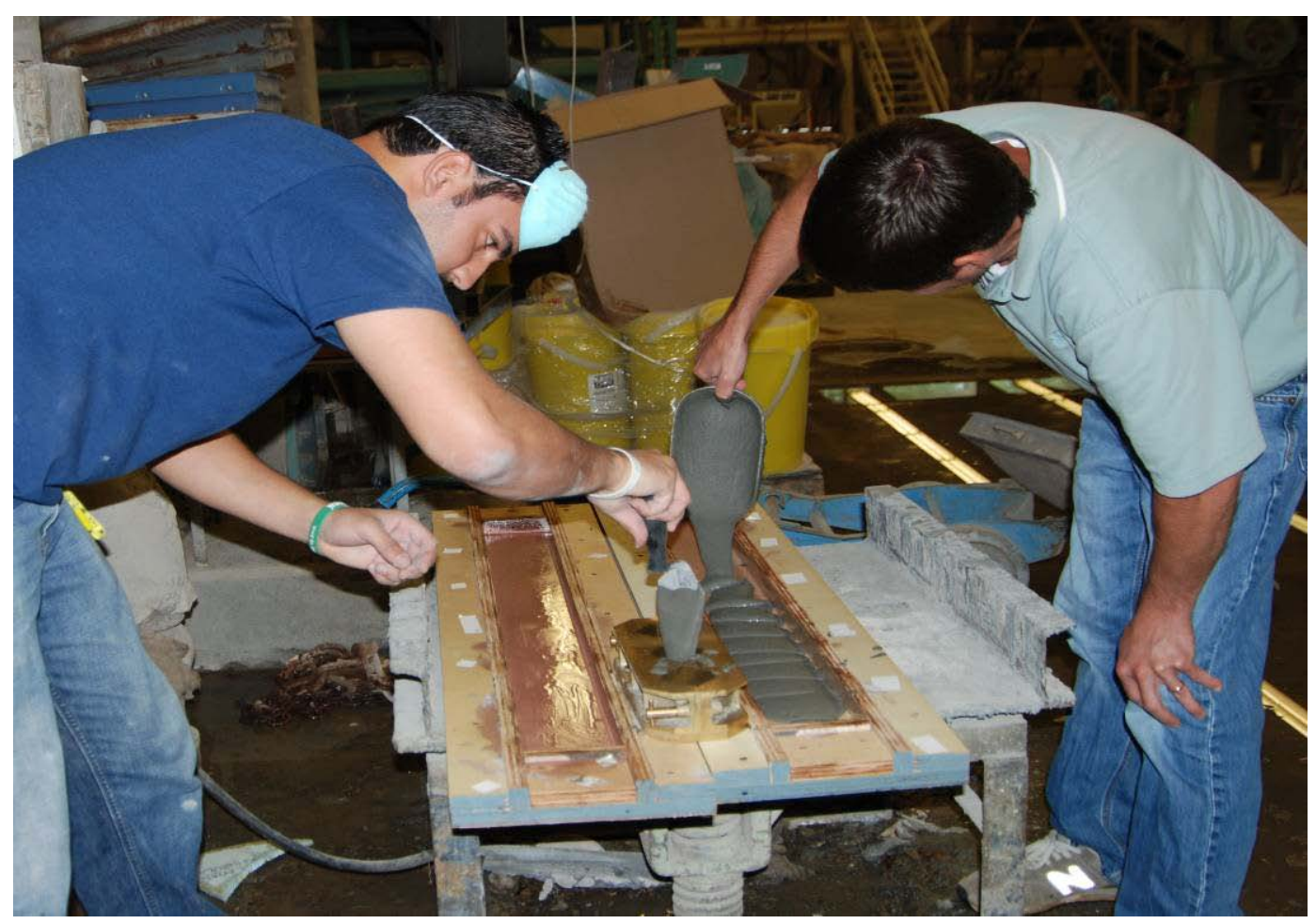

Figure 2. Beam and cube casting.

After casting, the cylindrical specimens underwent a prescribed curing regimen. The fresh specimens were placed in an environmentally controlled facility at $22^{\circ} \mathrm{C}$ and $100 \%$ humidity. After $24 \mathrm{hr}$, they were removed from their molds, returned to the facility, and remained there until 7 days age. The specimens were then submerged in a water bath that was maintained at $85^{\circ} \mathrm{C}$ for 4 days. Finally, they were dried in an oven for 2 days at $85^{\circ} \mathrm{C}$ for a cumulative curing time of 13 days.

After casting, the beam specimens were also placed in an environmentally controlled facility at $22^{\circ} \mathrm{C}$ and $100 \%$ humidity. After $24 \mathrm{hr}$, they were removed from their molds, returned to the facility, and remained there until 7 days age. The specimens were then placed in an insulated enclosure into which ambient pressure steam was cycled to maintain high humidity and a temperature of $85^{\circ} \mathrm{C}$ for 6 days. Following this procedure, the samples were cured for a cumulative curing time of 13 days.

\section{Quality control testing}

To assess the consistency between the various batches of Cor-Tuf (as listed in Tables 1 and 2), unconfined compression tests were performed on specimens cast from each batch. Both 50-mm cubes and 102-mm × 204-mm 
cylinders were prepared for the quality control testing, and the tests were conducted in accordance with the requirements of the American Society for Testing and Materials (ASTM) C109 and ASTM C39, as appropriate. Because of the length of the steel fibers in comparison to the size of the cubes, all compression cube tests were done on material without fiber reinforcement. However, due to the larger size of the cylinder samples, cylinder compression tests were conducted with and without fiber reinforcement, as appropriate for the test specimens being cast. In general, three or more unconfined compression test samples were prepared and tested for each batch of material. Unconfined compression testing results for each batch of material are shown in Table 4.

Table 4. Unconfined compression quality control test results.

\begin{tabular}{|c|c|c|c|c|}
\hline Batch No. & Specimen No. & Cube or Cylinder & f'c, MPa & Mean f'c, MPa \\
\hline \multirow{4}{*}{1} & 1 & cylinder (w/o fibers) & 180 & \multirow{4}{*}{183} \\
\hline & 2 & cylinder (w/o fibers) & 201 & \\
\hline & 3 & cylinder (w/o fibers) & 163 & \\
\hline & 4 & cylinder (w/o fibers) & 186 & \\
\hline \multirow{3}{*}{2} & 1 & cube (w/o fibers) & 182 & \multirow{3}{*}{175} \\
\hline & 2 & cube (w/o fibers) & 180 & \\
\hline & 3 & cube (w/o fibers) & 164 & \\
\hline \multirow{6}{*}{3} & 1 & cylinder (w/ fibers) & 194 & \multirow{6}{*}{188} \\
\hline & 2 & cylinder (w/ fibers) & 187 & \\
\hline & 3 & cylinder (w/ fibers) & 187 & \\
\hline & 4 & cylinder (w/ fibers) & 202 & \\
\hline & 5 & cylinder (w/ fibers) & 194 & \\
\hline & 6 & cylinder (w/ fibers) & 164 & \\
\hline \multirow{3}{*}{4} & 1 & cylinder (w/ fibers) & 179 & \multirow{3}{*}{194} \\
\hline & 2 & cylinder (w/ fibers) & 221 & \\
\hline & 3 & cylinder (w/ fibers) & 182 & \\
\hline \multirow{3}{*}{5} & 1 & cylinder (w/ fibers) & 211 & \multirow{3}{*}{204} \\
\hline & 2 & cylinder (w/ fibers) & 198 & \\
\hline & 3 & cylinder (w/ fibers) & 203 & \\
\hline \multirow{3}{*}{6} & 1 & cylinders (w/o fibers) & 178 & \multirow{3}{*}{182} \\
\hline & 2 & cylinders (w/o fibers) & 188 & \\
\hline & 3 & cylinders (w/o fibers) & 180 & \\
\hline
\end{tabular}




\section{Flexure tests, ASTM C1609}

Flexural response characteristics of the Cor-Tuf material were determined from four-point beam flexure tests performed, in accordance with the requirements of ASTM C1609. Testing was conducted on an MTS 810 testing machine configured with a 222-kN load cell (Omegadyne, Inc., LC402-50K, SN 267037), with the exception of experimental series 3, which was conducted with a 500-kN load cell (MTS Load Cell, Model 661.23A-02, SN 2351). The testing machine's loading head was monitored with a built-in linearly variable displacement transducer (LVDT), which provided displacement rate control during testing. Centerline displacement of the beams was recorded utilizing a spring-recoiled potentiometer, or yo-yo gage. Experimental series 1, 2, 4, and 5 were conducted with M150 string potentiometers ( 0 - to 38-mm measurement range) produced by Celesco Transducer Products, Inc.; however, a different type of yo-yo gage was used in series 3, and its specifications were not recorded. Load cell output and centerline displacement measurements were recorded on an external data acquisition system, providing load-deflection history for the beams' centerline response.

\section{Specimen preparation}

The flexure test specimens were cast in 1016-mm-long $\times$ 102-mm-wide beam molds, in accordance with the previously described casting process. Mold depths were $25 \mathrm{~mm}$ or $102 \mathrm{~mm}$, as appropriate for the specimens being prepared. With the exception of experimental series 5 , after curing and demolding, the 1016-mm-long beams were cut on a water-jet machine to provide two 356- $\mathrm{mm}$-long test specimens from each beam. The two specimens were cut from the center of the beam, leaving approximately 152-mm waste at each end. For series 5 , the beams were not cut down, and the full 1016-mm-long beams were tested. A 1016-mm-long beam sample (during curing) with cut locations for the 356- $\mathrm{mm}$ specimens is shown in Figure 3.

\section{Test setup}

To perform the four-point beam flexure tests, specimens were centered on a steel support structure placed in the MTS machine load frame. The support structure provided a 305-mm span between supports (914 mm for series 5), and a loading head applied two continuous strip-loads to the specimen at a distance of $102 \mathrm{~mm}$ from each support (305 $\mathrm{mm}$ for series 5). A 102-mm-deep specimen prepared for testing is shown in Figure 4. 


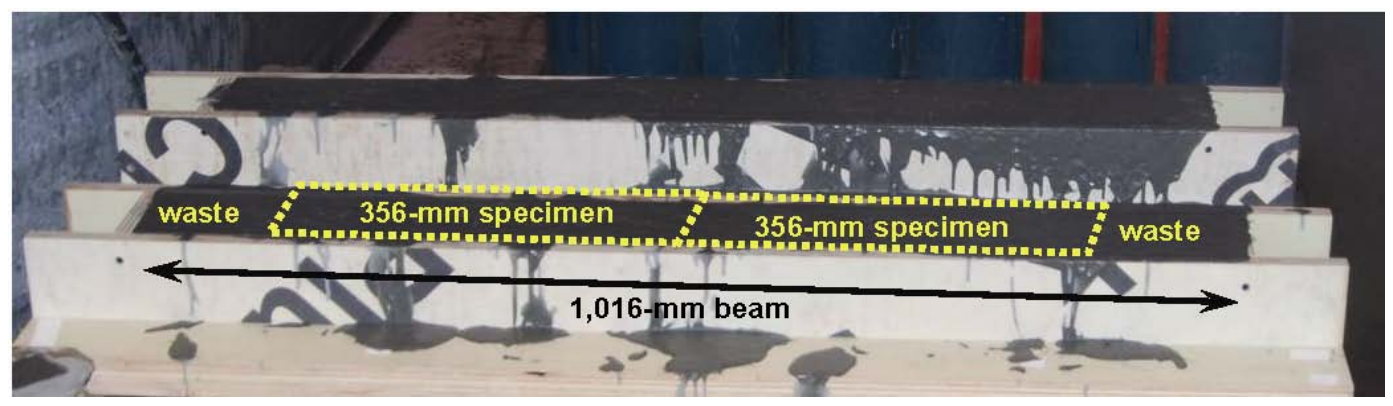

Figure 3. 1016-mm-long beam with cut locations for 356-mm test specimens.

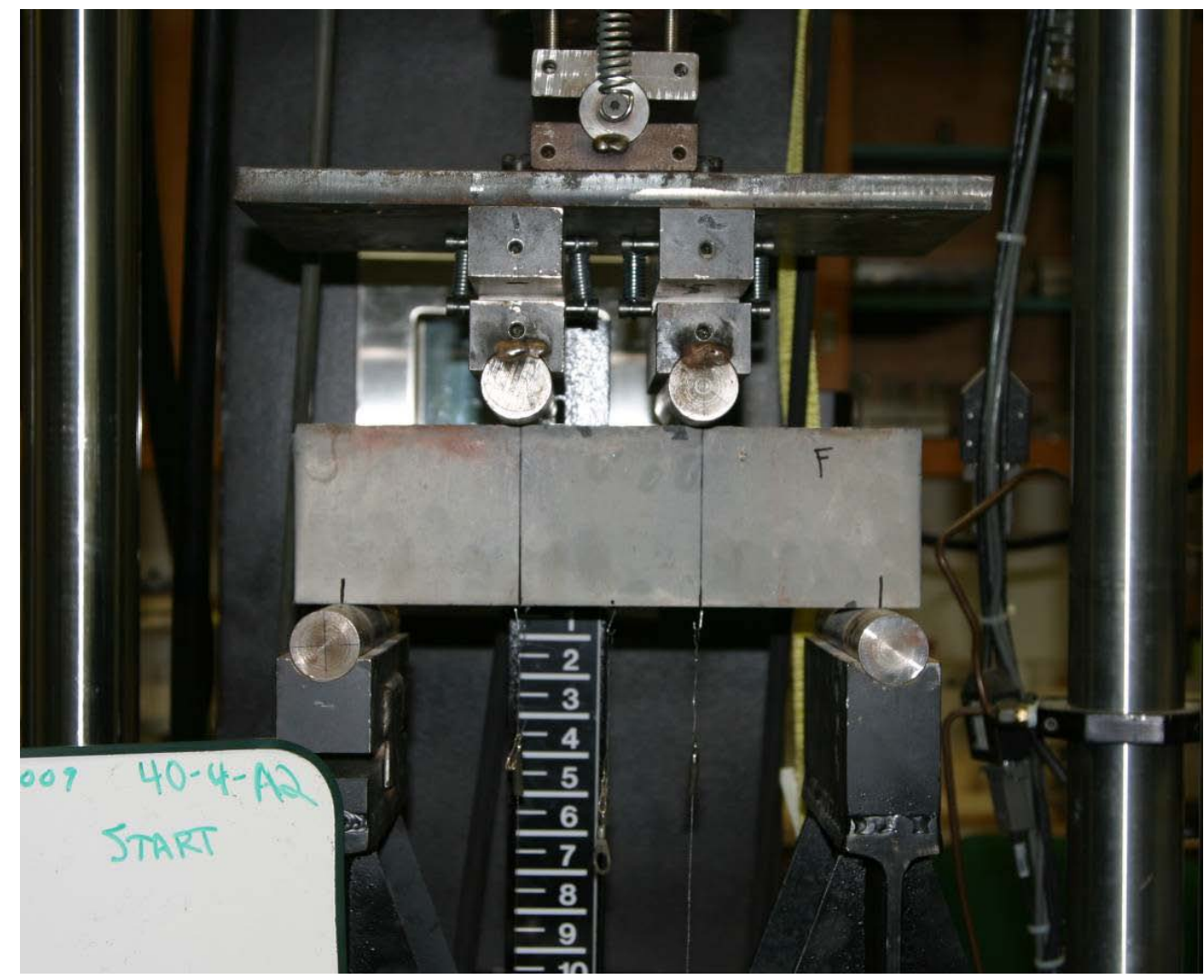

Figure 4. Typical flexure test setup (102-mm-deep beam, 305-mm span).

Testing was conducted utilizing a closed-loop setup with displacement rate control. For experimental series 1 through 4 , the initial displacement rate was set at $0.08 \mathrm{~mm} / \mathrm{min}$ and was increased to $0.16 \mathrm{~mm} / \mathrm{min}$ after the peak load was reached. Because of the greater centerline displacement expected in experimental series 5, the initial displacement rate was increased to $0.25 \mathrm{~mm} / \mathrm{min}$, and was subsequently increased to $0.5 \mathrm{~mm} / \mathrm{min}$ after peak load was reached. In each test, the specimens were centered on the support fixture, and the loading fixture was then lowered to within approximately $3 \mathrm{~mm}$ of the specimen surface. The tests were initiated at the specified 
displacement rate and continued until the applied load dropped to approximately $10 \%$ of the maximum load achieved.

To check the experiment setup, two control tests were conducted with structural steel test samples. In the control tests, the MTS machine was configured with the 222-kN load cell and the M150 string potentiometers. The tests were performed on a $356-\mathrm{mm} \times 102-\mathrm{mm} \times 6-\mathrm{mm}$ steel plate and a $356-\mathrm{mm} \times 102-\mathrm{mm} \times 102-\mathrm{mm}$ square structural steel tube $(6-\mathrm{mm}$ wall thickness), so that the experimental data could be compared with closedform displacement solutions. The steel plate during testing is shown in Figure 5 .

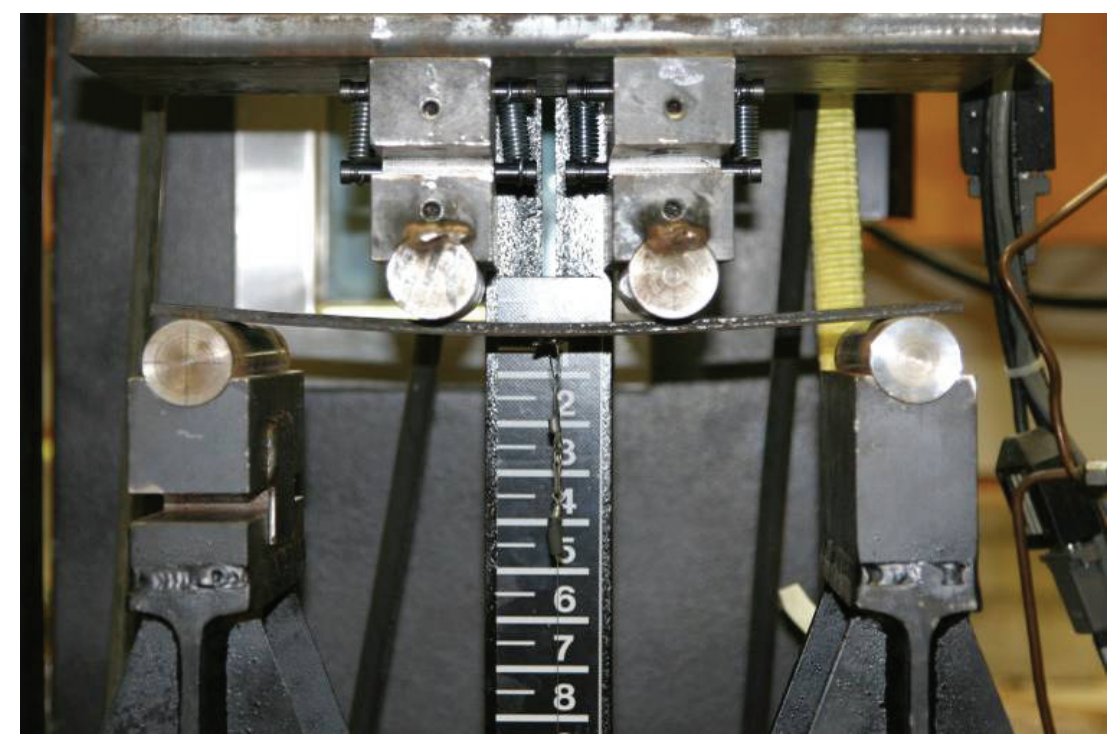

Figure 5. Four-point flexure steel plate control test.

Data from the steel plate and structural tube tests are shown in Figures 6 and 7, respectively. For each test, the closed-form solution for centerline displacement, calculated by Equation 1, is also shown.

$$
\delta=\frac{P a}{24 E I}\left(3 l^{2}-4 a^{2}\right)
$$

where:

$\delta=$ centerline displacement, $\mathrm{mm}$

$\mathrm{P}=$ load at each loading point, i.e., one-half of load cell reading, $\mathrm{N}$

$\mathrm{a}=$ distance between loading points, $\mathrm{mm}$

$\mathrm{E}=$ Young's modulus, $\mathrm{MPa}$

$I=$ moment of inertia, $\mathrm{mm}^{4}$

$l=$ beam span, $\mathrm{mm}$. 


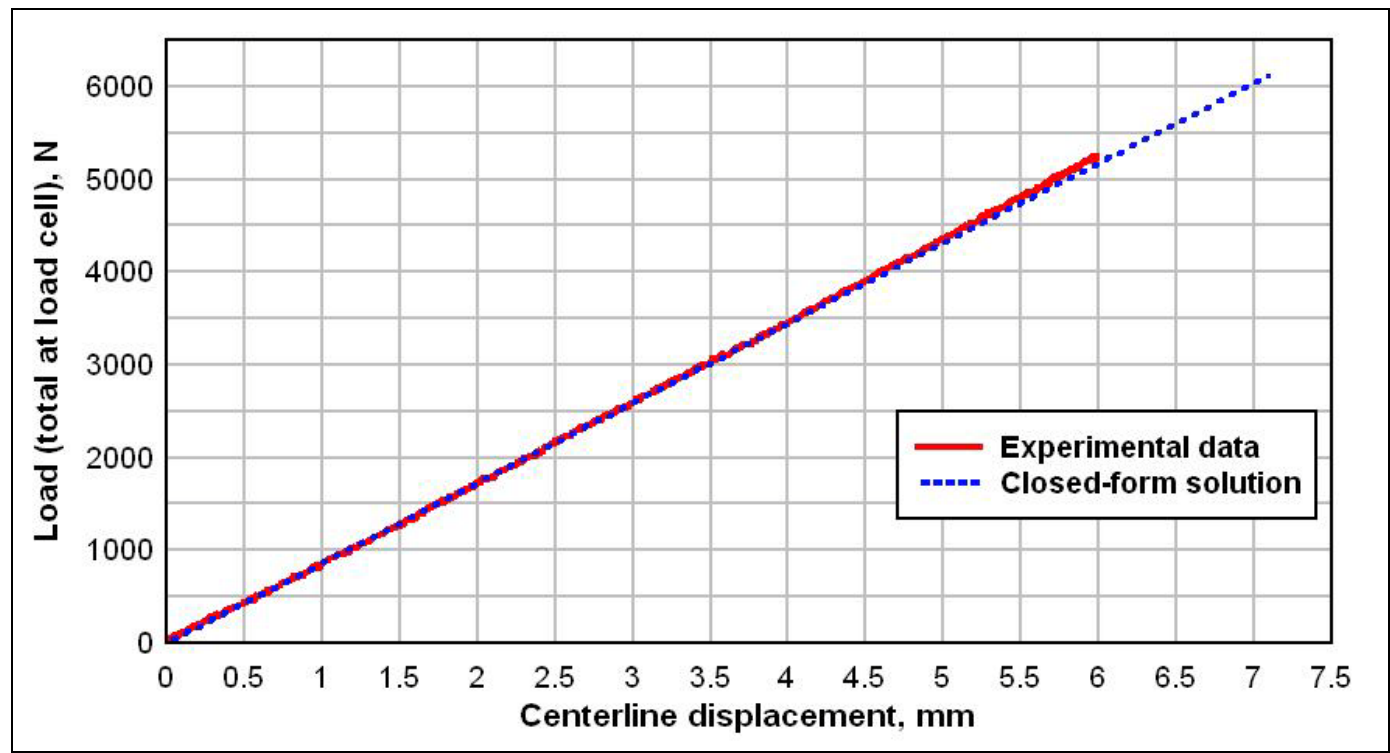

Figure 6. Steel plate control test, experimental data and closed-form solution.

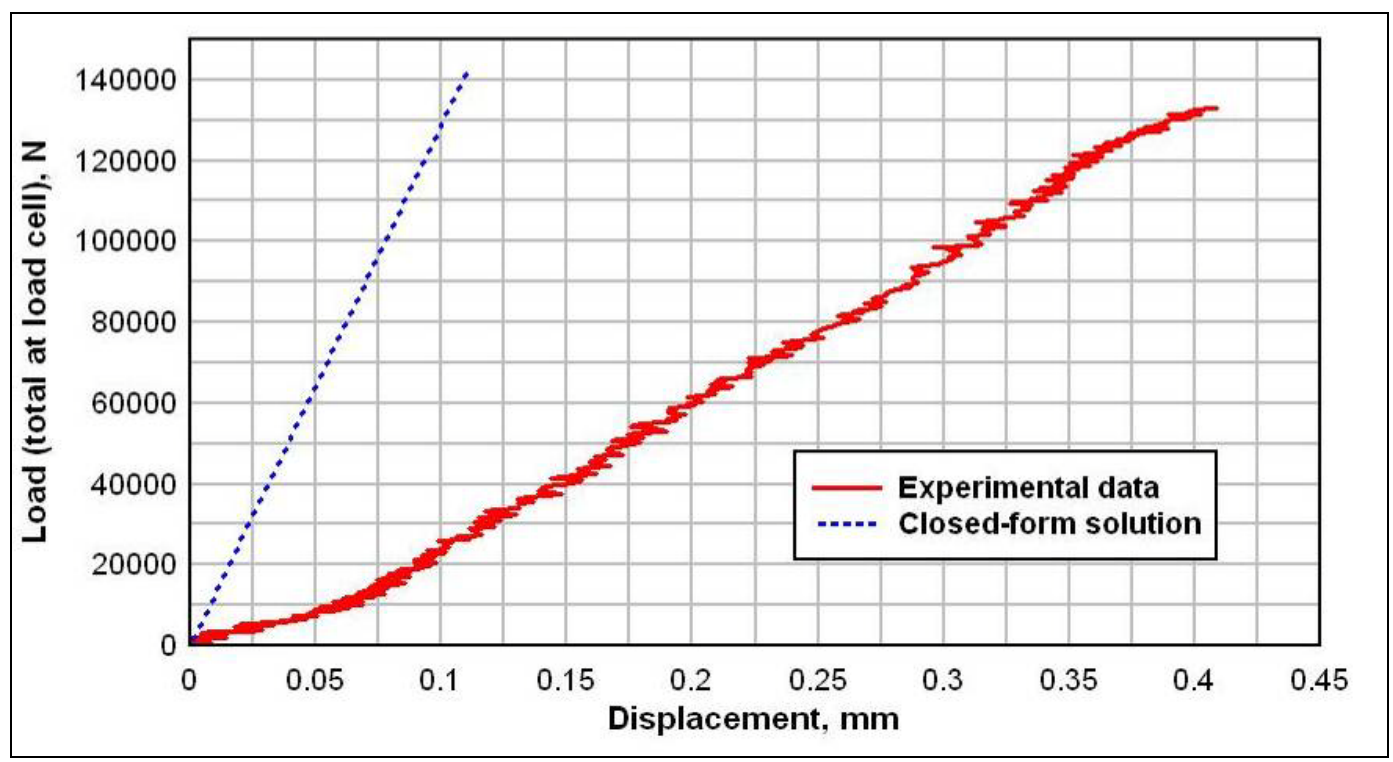

Figure 7. Steel tube control test, experimental data and closed-form solution.

As seen in Figure 6, the steel plate test was conducted to a maximum load of approximately $5500 \mathrm{~N}$. Over this range of loads, the experimental data were highly linear and provided a near exact match to the closed-form estimate of response. From these results, the experimental setup provided a very accurate measurement of response for the given loading range.

Utilizing a similar test setup, the structural steel tube was tested to a maximum loading of approximately $130,000 \mathrm{~N}$, as shown in Figure 7. The closed-form solution is also given in the figure, and from the plot, two significant observations were made. First, it was noted that the measured 
response was somewhat bilinear, with an initial stiffness observed up to a load of approximately $10,000 \mathrm{~N}$, followed by a stiffer response to the maximum load. This bilinear response should not be expected for a basic structural steel member; and therefore, the initial softness was believed to be the result of "seating" of the test support fixture. Observance of the seating effect was magnified in this case due to the very small maximum displacement measured, causing it to have a greater effect on results. Note that this same bilinearity (and assumed seating) was observed in the concrete specimen tests and is further addressed in Chapter 4 . The second significant observation made from Figure 7 was the difference between the stiffness of the closed-form solution and the experimental data. Comparing the slope of the experimental data curve (above load of 10,000 N) to the closed-form solution, stiffness values of approximately 374,000 N/mm and $1,287,000 \mathrm{~N} / \mathrm{mm}$ were calculated, respectively. The significant difference between theoretical and experimental results is believed to have arisen from inapplicability of the closed-form solution (which is based on simple beam bending theory) to the thicker beam and is further addressed in Chapter 3.

\section{Splitting tensile tests, ASTM C496}

Indirect tensile response characteristics of the Cor-Tuf material were determined from splitting tensile tests performed, in accordance with the requirements of ASTM C496. Testing was conducted on a Baldwin 1.9 MN testing machine. The test was performed in a load controlled format, with an applied loading rate of $1260 \mathrm{~N} / \mathrm{s}$.

\section{Specimen preparation}

The $102 \mathrm{~mm} \times 204 \mathrm{~mm}$ splitting tensile test cylinders were cast in plastic cylinder molds, in accordance with the ASTM method. The plastic molds were equipped with tight fitting lids to ensure that the cylinders remained round at the top, as well as at the bottom. The cylinders were allowed to set for $24 \mathrm{hr}$ in their molds, while residing in an ambient temperature, 100\% humidity environment (fog room). The molds were stripped from the cylinders after this setting period, and the cylinders were then returned to the fog room until an age of 7 days. The cylinders were then placed into a water bath that was gradually heated to $85^{\circ} \mathrm{C}$, where they then dwelled for 4 days. The cylinders were finally removed from the water bath and placed in a dry $85^{\circ} \mathrm{C}$ oven for 2 days, for a cumulative total of 13 days curing time. The cylinders were then allowed to cool to ambient temperature, and the 
nonmolded end was sawed flat and perpendicular to the sides of the specimen before testing.

\section{Test setup}

The setup for the splitting tensile tests followed the prescription given in ASTM C496. The test jig provided parallel line loads 180 deg apart on the cylinder sides. 


\section{Finite Element Analysis of Flexural Test Setup}

As shown in Figures 6 and 7, data from the thin steel plate control test closely matched the closed-form solution for centerline displacement, while the structural tube test data and closed-form predictions deviated significantly. This same trend was later observed in the Cor-Tuf beam tests, where data for the 25-mm-thick beams matched closed-form predictions, while data for the 102-mm-thick beams were much softer than the analytically calculated values (using the same assumed modulus for both cases). As a part of this experimental program, it was desired to calculate Young's modulus, E, for the material, which could be done with an analytical expression such as given in Equation 1. However, in consideration of the above observations, it was necessary to further investigate the deviating trend and applicability of the closed-form expression. Therefore, based on the assumption that the observed deviation was a result of inapplicability of the simple beam bending equation to the thick beam condition, a finite element (FE) analysis was conducted to investigate the response of thin and thick beams when loaded as done in the experimental configuration.

\section{Finite element model}

The ABAQUS code (ABAQUS 2005) was used to perform the FE analyses. Two conditions were modeled, one based on a test sample with dimensions of 356- $\mathrm{mm} \times 102-\mathrm{mm} \times 25-\mathrm{mm}$ and one based on a sample with dimensions of 356-mm $\times 102-\mathrm{mm} \times 102-\mathrm{mm}$. Results from each model, in the form of applied load versus centerline displacement, were compared with the analytically calculated response in order to determine whether the closedform expression could be appropriately used in both situations.

The test samples were meshed using linear hexadral elements (ABAQUS element type C3D8), and a full integration scheme was used to prevent spurious results due to hourglass formation. Pin and roller boundary conditions were applied to the model, providing a total beam span of $305 \mathrm{~mm}$ between supports. Surface tractions were applied to the top surface of the beams at a distance of $102 \mathrm{~mm}$ from each support, in accordance with the loading condition in the experimental configuration. Because the 
objective of the analyses was to investigate the initial stiffness of the beams, a simple elastic material model was used. In the material model, Poisson's ratio, $v$, was specified as 0.22 and Young's modulus, E, was specified as $38 \mathrm{GPa}$. These material properties were approximated from data given by Williams et al. (2009) and were expected to be similar to the properties of the Cor-Tuf material used in this study. A discretized test sample (102-mmthick) with applied loads and boundary conditions is shown in Figure 8.

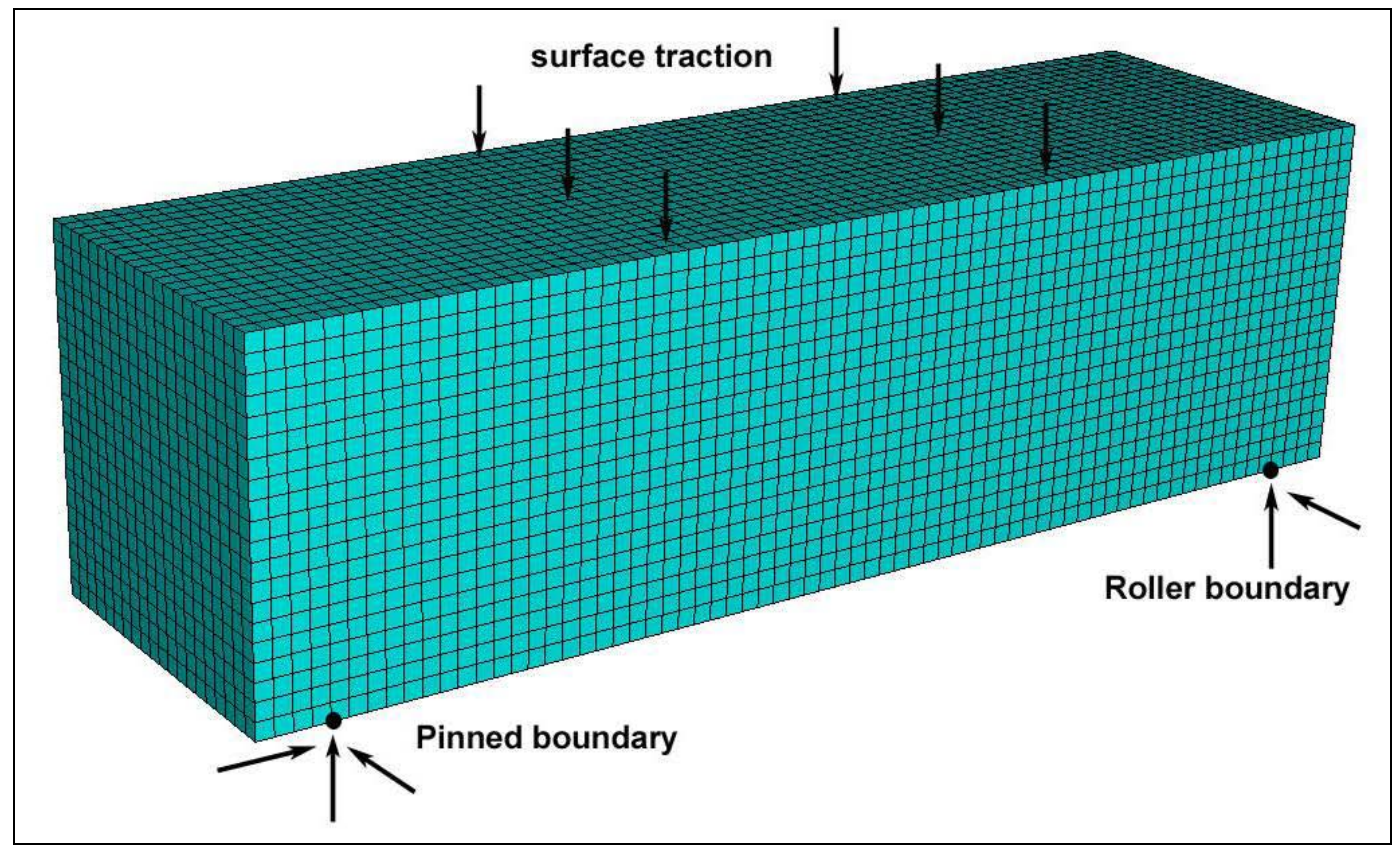

Figure 8. Discretized test sample with load and boundary conditions $(356-\mathrm{mm} \times 102-\mathrm{mm} \times 102-\mathrm{mm})$.

\section{5-mm-thick beam}

As part of the FE study, an h-refinement analysis was conducted to evaluate subjectivity of the results based on mesh size and to identify the converged FE displacement solution. Three discretizations were evaluated, utilizing element sizes of $12.5 \mathrm{~mm}, 5 \mathrm{~mm}$, and $2.5 \mathrm{~mm}$. Correspondingly, these discretizations provided two, five, and ten elements through the thickness of the beam. Results from the analyses, in the form of applied load versus centerline displacement, are shown in Figure 9. Also shown in Figure 9 is the closed-form solution for centerline displacement utilizing Equation 1 and the material properties assumed in the FE model. 


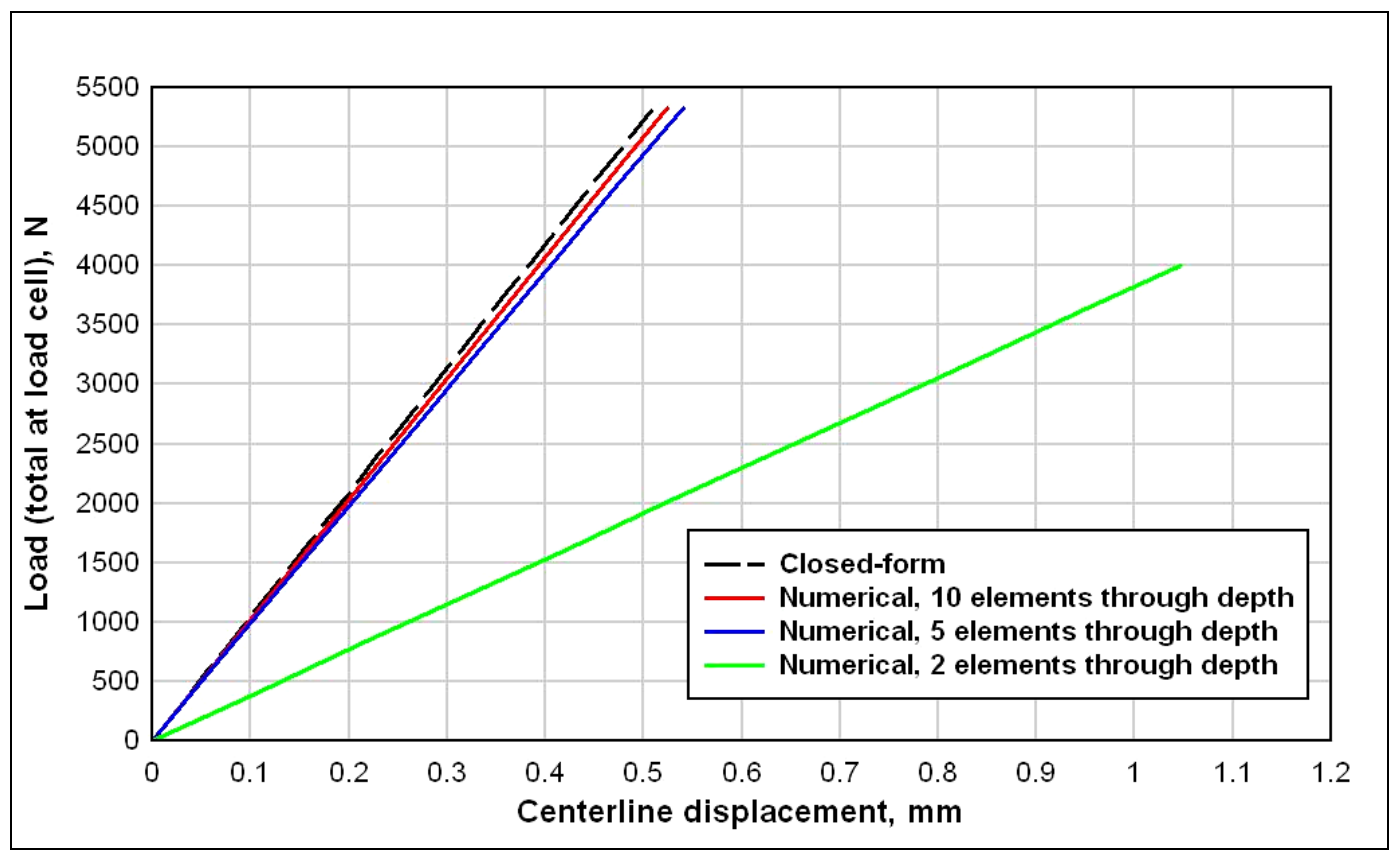

Figure 9. FE results and closed-form solution for 25-mm-thick beam.

As seen from the results, the model reasonably converged with the $2.5-\mathrm{mm}$ elements. Furthermore, the numerical results converged to the closedform solution, indicating that the analytical expression appropriately predicted the thin-beam response.

\section{2-mm-thick beam}

Similar to the 25-mm beam study, an h-refinement analysis was also conducted for the 102-mm-thick beam case. Three discretizations were again evaluated, using the same element sizes of $12.5 \mathrm{~mm}, 5 \mathrm{~mm}$, and $2.5 \mathrm{~mm}$. Correspondingly, these discretizations provided 8, 20, and 40 elements through the thickness of the 102-mm-thick beam. Results from the analyses, in the form of applied load versus centerline displacement, are shown in Figure 10. Also shown in Figure 10 is the closed-form solution for centerline displacement utilizing Equation 1 and the material properties assumed in the FE model.

As in the thin-beam case, the numerical solution reasonably converged with the 2.5-mm element size. However, in contrast to results for the 25-mm beam, the numerical solution did not converge to the closed form. Rather, the numerical model indicated that the apparent stiffness of the 102-mm-thick beam was much softer than that predicted by the closedform solution, which was qualitatively similar to observations made from the structural steel tube control test (and similar to results observed for 
the 102-mm-thick Cor-Tuf beams). Therefore, it was concluded that in the case of the thicker beams, the analytical solution based on simple beam bending was not applicable for the calculation of initial beam stiffness (and correspondingly for calculation of $\mathrm{E}$ from the experimental results). The reason for the variation between the analytical and numerical solutions is believed to be excessive shear-induced displacement in the thicker beams, which was not considered in the simple analytical bending equation.

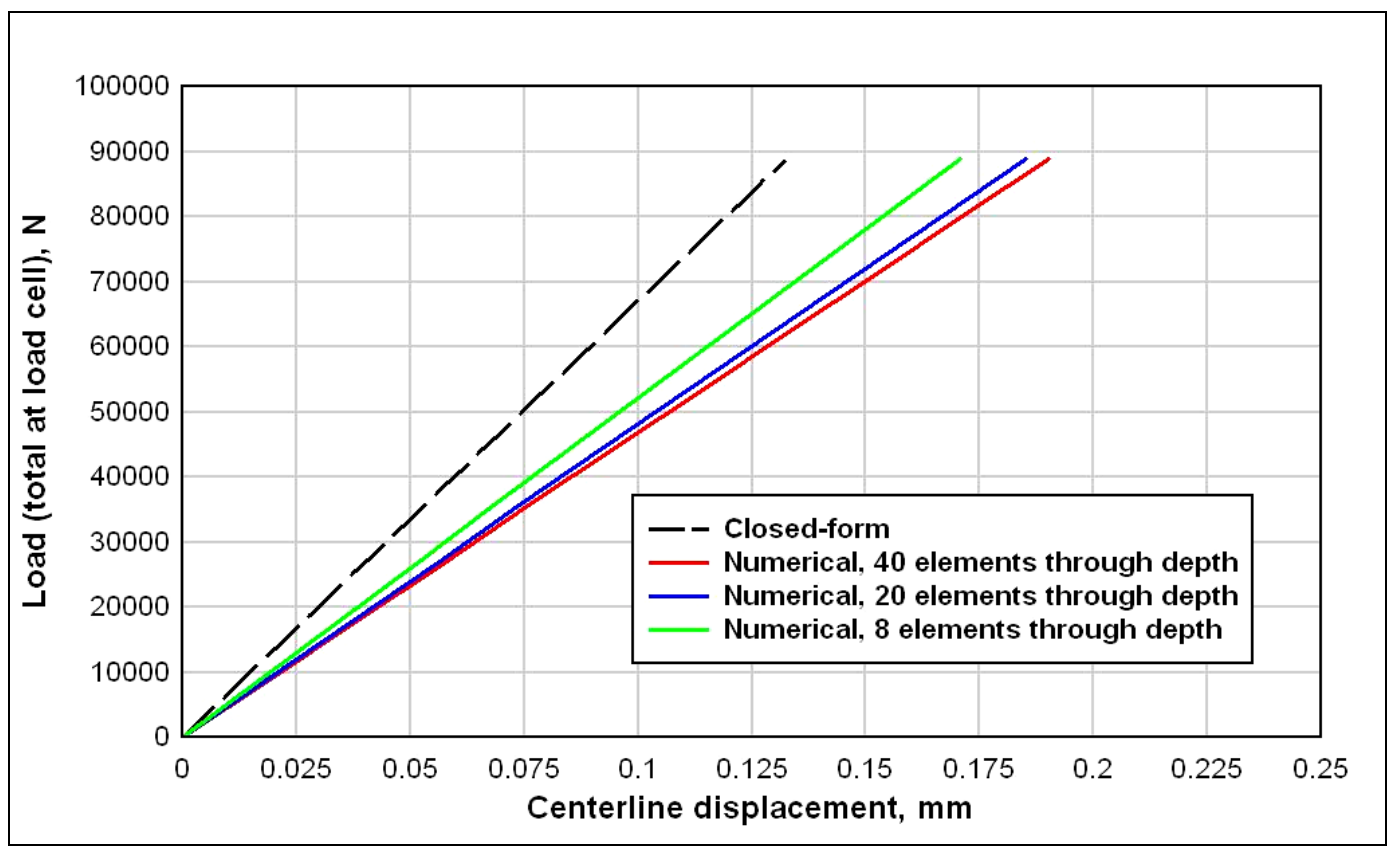

Figure 10. FE results and closed-form solution for 102-mm-thick beam.

\section{Maximum flexural stress, closed-form versus numerical solutions}

In addition to initial stiffness characteristics, it was also desired to determine Cor-Tuf's maximum flexural strength from the experimental data. Therefore, in conjunction with the numerical investigation of initial stiffness, comparisons were also made between the analytical and numerical flexural stresses. To analytically determine maximum flexural stress in the beams, Equation 2 was utilized.

$$
\sigma=\frac{6 \mathrm{~Pa}}{\mathrm{bd}^{2}}
$$

where:

$\sigma=$ maximum tensile stress in the specimen, $\mathrm{MPa}$

$\mathrm{P}=$ load at each loading point, i.e., one-half of load cell reading, $\mathrm{N}$ 

$\mathrm{a}=$ distance between loading points, $\mathrm{mm}$
$\mathrm{b}=$ width of the specimen, $\mathrm{mm}$
$\mathrm{d}=$ depth of the specimen, $\mathrm{mm}$.

Numerically determined flexural stresses in the 25-mm and 102-mm beams are shown in Figures 11 and 12, respectively. In the case of the 25-mm-thick beam, the maximum stress from the numerical model was $20 \mathrm{MPa}(4670 \mathrm{~N}$ applied load). In comparison, the analytically calculated stress at the same load level was $21.7 \mathrm{MPa}$, indicating an error of approximately $8 \%$ between the numerical and analytical results. Because stress is determined as a derivative of displacement in the numerical model, and lower-order elements were used in the discretization, it is expected that the computed stresses would converge with results from the numerical model with further model refinement. This was validated by utilizing quadratic hexahedral elements in the same model, which yielded a maximum tensile stress of approximately 21.2 MPa. Therefore, the numerical and analytical stresses were considered to be in general agreement for the thin-beam case.

Similarly, the numerical and analytical stresses for the thick beam case were 26.8 MPa and 25.6 MPa, respectively, at an applied load level of 89,000 N. Again, the results were in general agreement, and it was concluded that the analytical expression for maximum tensile stress was applicable for both the thin- and thick-beam conditions.

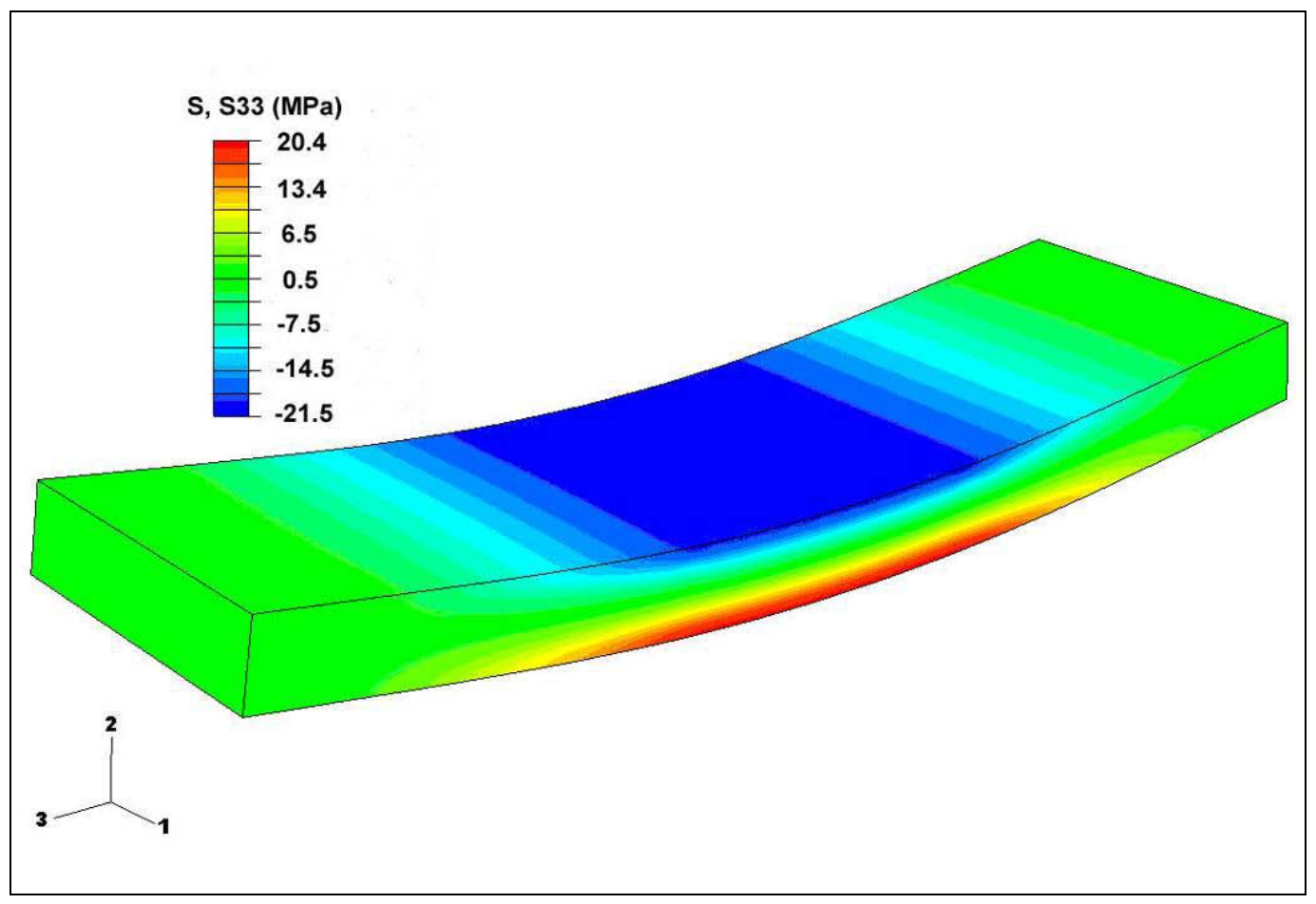

Figure 11. FE calculated flexural stress in $25-\mathrm{mm}$ beam (2.5-mm element size). 


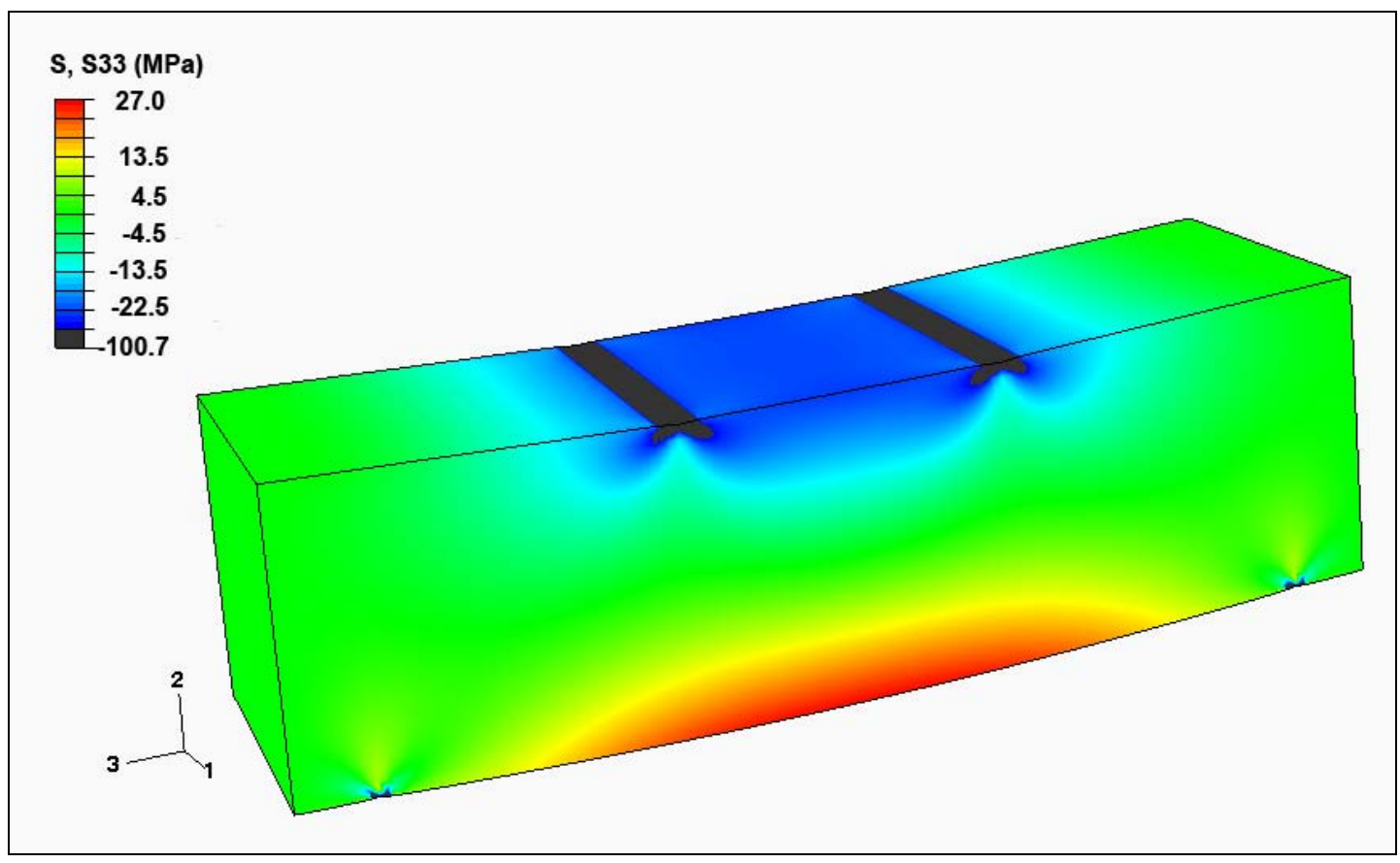

Figure 12. FE calculated flexural stress in $102-\mathrm{mm}$ beam (2.5-mm element size). 


\section{Flexure Test Results}

As indicated in Table 1, five experimental series were conducted to evaluate flexural response characteristics of the Cor-Tuf material. Reinforcement conditions, beam depth, and beam span were varied between series to determine their effect on flexural response. Summaries of each series, including the experimental results, are provided in the following sections. Exact cross section dimensions and the calculated moment of inertia for each test specimen are given in Appendix A.

\section{Experimental series 1}

Experimental series 1 was conducted utilizing 356- $\mathrm{mm} \times 102-\mathrm{mm} \times 25-\mathrm{mm}$ beam specimens without fiber reinforcement, thus providing a measure of the flexural characteristics of the unreinforced Cor-Tuf matrix. From Table 4, the mean unconfined compressive strength for specimens NF-1 through NF-4 (batch 1) was $183 \mathrm{MPa}$. The mean strength of specimens NF-5 and NF-6 (batch 3) is reported as $188 \mathrm{MPa}$. However, the batch 3 compression strength specimens were tested with fibers, which were added after the two beam specimens were made. Therefore, the unconfined strength for samples NF-5 and NF-6 (without fibers) is also assumed to be approximately $183 \mathrm{MPa}$.

Six tests were conducted in this series; however, one of the specimens (NF-2) failed outside of the loading points, and the data were discarded. Test results, in terms of total applied load versus centerline displacement, are shown in Figure 13. Also given in Figure 13 is the closed-form displacement solution based on assumed E values of $34.5 \mathrm{GPa}$ and $38 \mathrm{GPa}$.

As seen from the data, the flexural response to failure was relatively linear, although samples NF-1, NF-3, and NF-5 showed some bilinearity. As discussed for the control tests, the bilinearity was attributed to seating of the test fixture and was not expected to be a true characteristic of the material. Disregarding the initial response of the material (i.e., response below approximately $1000 \mathrm{~N}$ ), the mean Young's modulus for the specimens was calculated to be $38.3 \mathrm{GPa}$, with a standard deviation of $2.6 \mathrm{GPa}$ and a coefficient of variation (CoV) of $7 \%$. From comparison to the closed-form solution, slope of the experimental data reasonably matched 
that of the calculated response, indicating that the assumed Young's moduli provided a reasonable range of estimated values for the material.

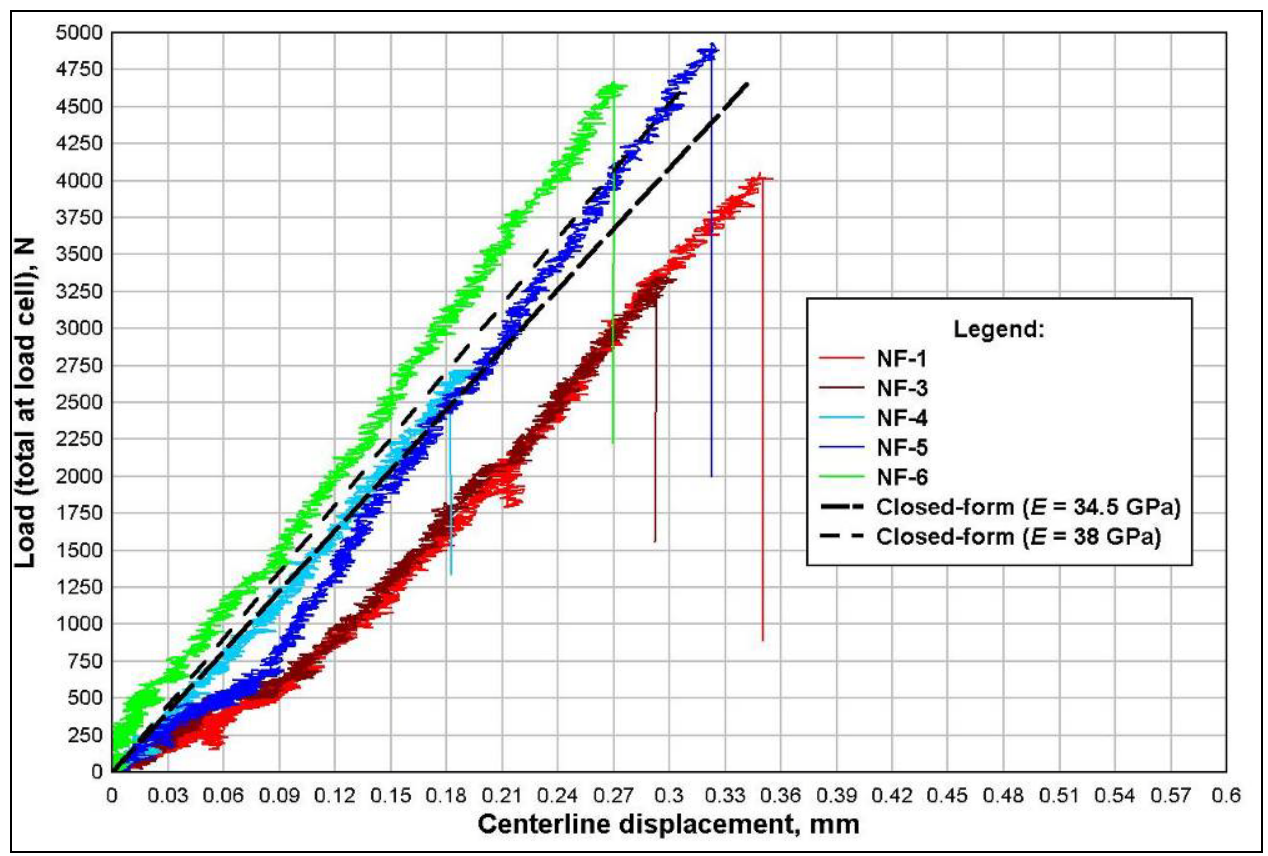

Figure 13. Load-displacement response, $25-\mathrm{mm}$ beams without fibers.

In addition to Young's modulus, flexural strength of the material was determined from the data utilizing equation 2 . Based on peak load from each experiment, mean flexural strength was calculated to be $14.5 \mathrm{MPa}$, with a standard deviation of $3.1 \mathrm{MPa}$ and a $\mathrm{CoV}$ of $21 \%$. Note that, from the data, it was observed that two specimens (NF-3 and NF-4) failed at significantly lower loads than the others. Therefore, treating specimens NF-3 and NF-4 as outlier data points, mean flexural strength was recalculated to be 16.6 $\mathrm{MPa}$, with a standard deviation of $1.1 \mathrm{MPa}$ and a $\mathrm{CoV}$ of $6 \%$.

The failed specimens from experimental series 1 are shown in Figure 14.

\section{Experimental series 2}

Experimental series 2 was conducted utilizing 356- $\mathrm{mm} \times 102-\mathrm{mm}$ $\times 102-\mathrm{mm}$ beam specimens without reinforcement, thus providing a measure of the flexural characteristics of the unreinforced Cor-Tuf matrix. From Table 4, the mean unconfined compressive strength of the specimens (batch 1) was $183 \mathrm{MPa}$. 


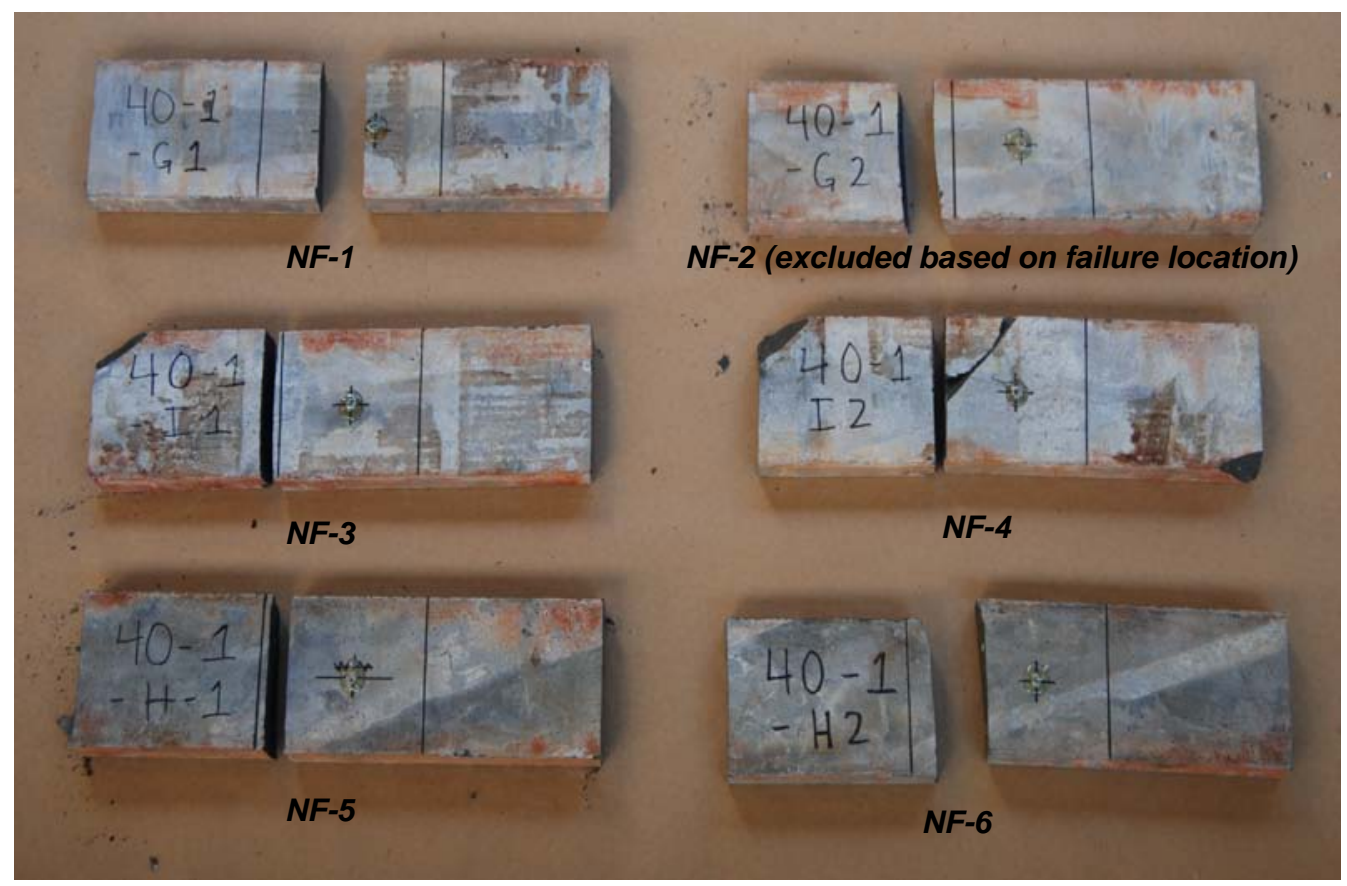

Figure 14. Series 1 failed flexural test specimens, $25-\mathrm{mm}$ beams without fibers.

Six tests were conducted in this series; however, one of the specimens (NF-11) failed outside of the loading points, and the data were discarded. Test results, in terms of total applied load versus centerline displacement, are shown in Figure 15. Also given in Figure 15 are the numerical solutions for centerline displacement based on assumed Young's moduli of $34.5 \mathrm{GPa}$ and $38 \mathrm{GPa}$.

In contrast to series 1 , greater bilinearity was observed in the raw data from series 2. As seen in Figure 15, the specimens first appeared to exhibit an initial stiffness, which was much less than numerically predicted. Then, at a load between 12,000 N and 18,000 N, the specimens transitioned to a stiffer response, which more closely resembled that of the numerical estimates. However, as previously discussed, the initially soft response (and resulting bilinearity) was attributed to seating of the test fixture, and was therefore assumed an artifact of the experimental setup. Based on this assumption, the data were adjusted, as shown in Figure 16, to correct for the seating effect. The data adjustment was performed by first truncating the data sets to remove the initial response. The truncation was followed by shifting of the data based on the assumption of linear response over the full range of applied loads (i.e., the data were shifted, so that the remaining portions of the response curves projected back to the point of zero load and zero displacement). The adjusted data sets, along with the numerical response predictions, are shown in Figure 16. 


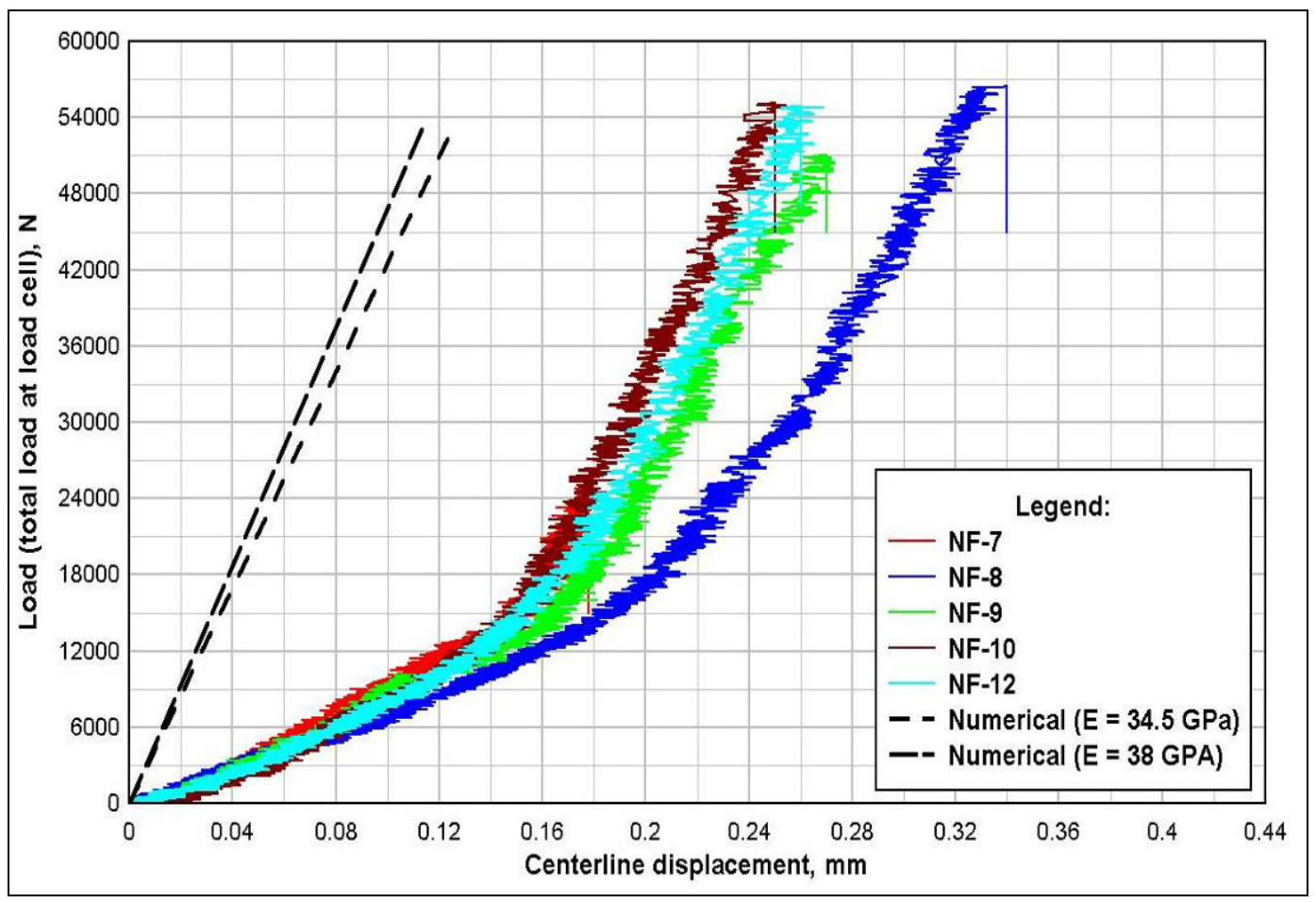

Figure 15. Load-displacement response, 102-mm beams without fibers.

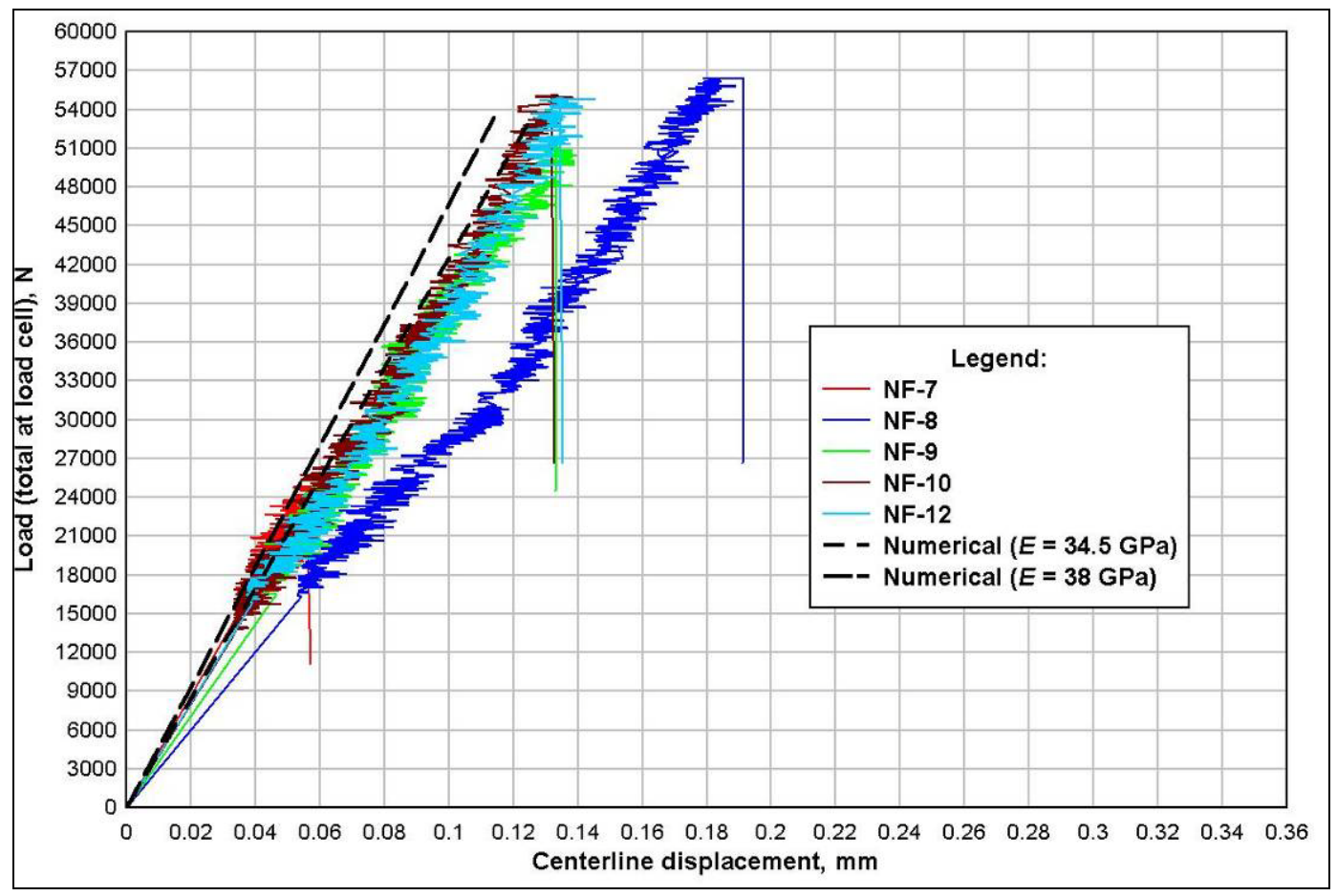

Figure 16. Adjusted load-displacement response, 102-mm beams without fibers. 
Due to the nature of the thicker beams' response (as discussed in Chapter 3), equation 1 could not be utilized to directly calculate Young's modulus from the experimental data in series 2 . However, from comparison of the experimental data and numerical solutions in Figure 16, it can be seen that the assumed range of moduli values ( $34.5 \mathrm{GPa}$ to $38 \mathrm{GPa}$ ) closely matched the experimental results. Therefore, it was concluded that the assumed range of values provided a reasonable estimate of $E$ for the material.

As with series 1, flexural strength of the material was determined from the data utilizing equation 2 . Based on peak load from each experiment, mean flexural strength was calculated to be $13.7 \mathrm{MPa}$, with a standard deviation of 3.8 MPa and a $\mathrm{CoV}$ of $27.6 \%$. From the data, it was observed that one specimen (NF-7) failed at a significantly lower load than the other specimens. Therefore, treating specimen NF-7 as an outlier, mean flexural strength was recalculated to be $15.3 \mathrm{MPa}$, with a standard deviation of $0.8 \mathrm{MPa}$ and a $\mathrm{CoV}$ of $5 \%$.

The failed specimens from experimental series 2 are shown in Figure 17.

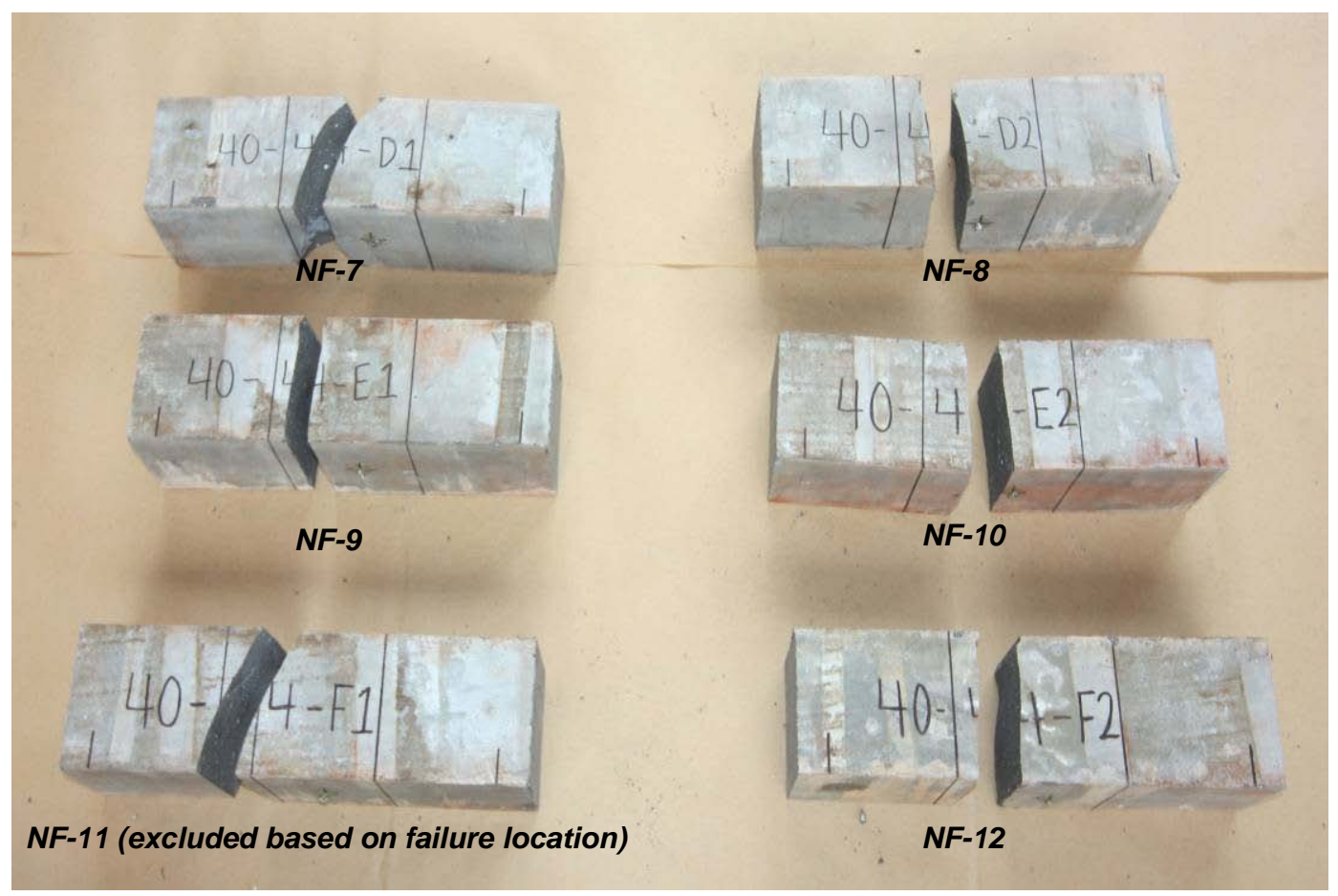

Figure 17. Failed flexural test specimens, 102-mm beams without fibers. 


\section{Experimental series 3}

Experimental series 3 was conducted utilizing 356- $\mathrm{mm} \times 102-\mathrm{mm} \times 25-\mathrm{mm}$ beam samples with fiber reinforcement, thus providing a measure of the reinforced material's flexural characteristics for comparison to the unreinforced data (series 1). From Table 4, the mean unconfined compressive strength of the specimens (batch 2) was $175 \mathrm{MPa}$. Note that, for this batch, the unconfined compressive strength was determined using unreinforced cubes, although the beam samples contained fiber reinforcement.

Nine tests were conducted in this series; however, one of the specimens (F3) failed outside of the loading points, and the data were discarded. Test results, in terms of total applied load versus centerline displacement, are shown in Figure 18.

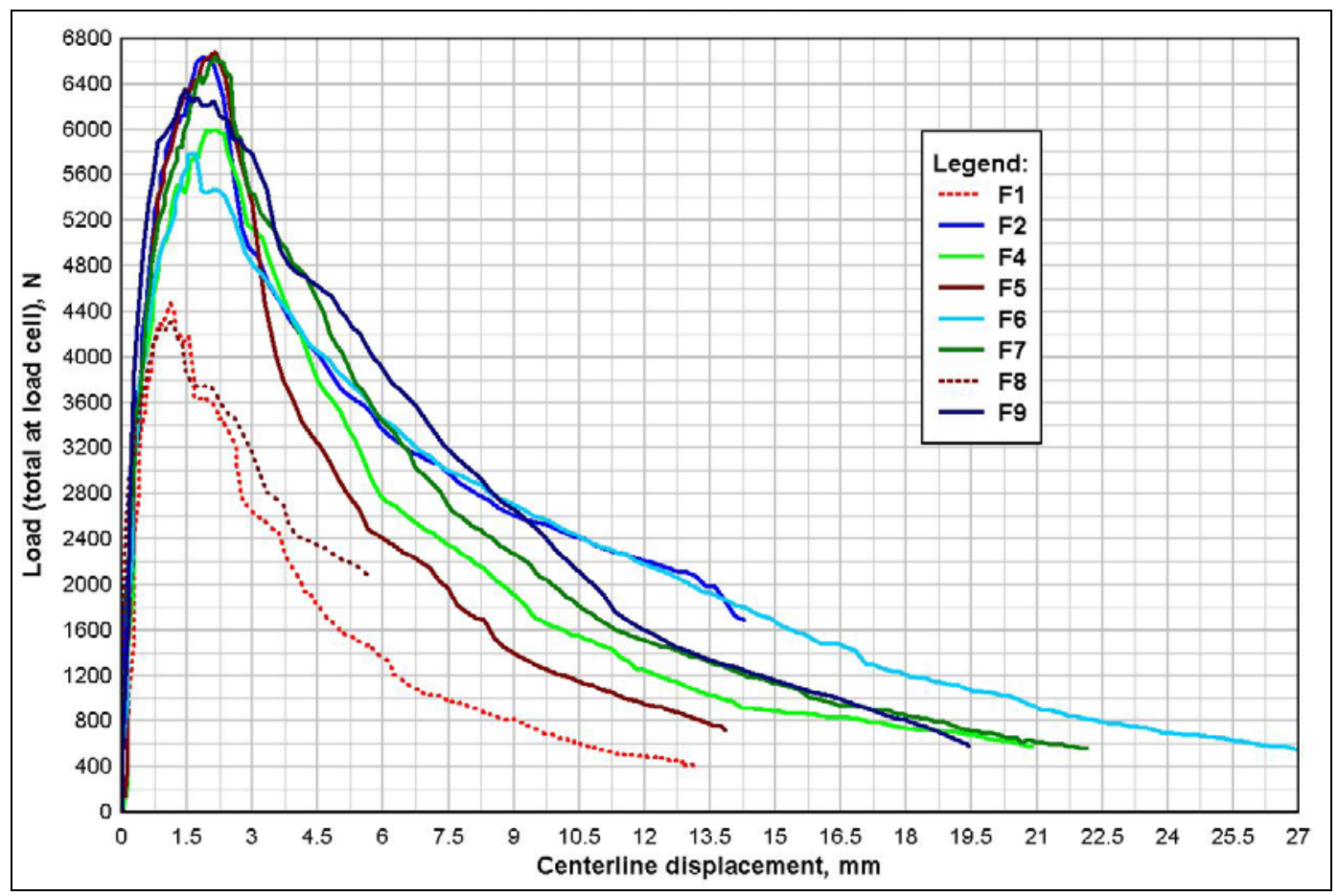

Figure 18. Load-displacement response, 25-mm beams with fibers.

From the data, initial response of the material was relatively linear, with little or no bilinearity observed. From the initial linear response, mean Young's modulus was calculated to be $33.8 \mathrm{GPa}$. After the initial linear response phase, the material transitioned to a nonlinear response until reaching peak load, which was then followed by a softening response until complete failure. Prior to peak load, response of the specimens was relatively uniform. Some variability was observed in peak load (excluding 
specimens F1 and F8); however, the greatest variability was observed in the post peak response. As seen in Figure 18, at a post peak load of $400 \mathrm{~N}$, centerline displacement for the specimens ranged from approximately $13.5 \mathrm{~mm}$ to $27 \mathrm{~mm}$. This apparent variability in post peak ductility was suspected to be the result of two effects, one being a true material characteristic and the other being an artifact of the experiment. First, because the post peak softening response was directly governed by the reinforcement fibers, the stochastic distribution and orientation of fibers within the material contributed to the variability in maximum displacement. This stochastic effect is a fundamental aspect of this type of randomly reinforced material and must be jointly addressed by material processing considerations to promote uniformity in fiber distribution and by use of nondeterministic calculation techniques to estimate material failure characteristics. In addition to stochastic effects, the method of measurement for centerline displacement and basic nature of the post peak response were also possible causes of the apparent variability in maximum displacement. As the specimens fractured during post peak response, a single plastic hinge progressively formed, which transitioned the specimens from a smooth deflected shape (with maximum displacement at the centerline) to two linear segments connected at the hinge point (i.e., point of failure). This considered, the location of the hinge subjectively influenced the centerline displacement measurements, partially leading to the observed variability in maximum displacement at failure. Note that, in this study, distinctions were not made between the influence of fiber distribution and hinge formation on the maximum displacement at specimen failure.

As with the previous series, flexural strength of the material was determined from the data utilizing equation 2. Based on peak load from each experiment, mean flexural strength was calculated to be $22 \mathrm{MPa}$, with a standard deviation of $3.9 \mathrm{MPa}$ and a $\mathrm{CoV}$ of $17.5 \%$. From the data, it was observed that two specimens (F1 and F8) failed at significantly lower loads than the others. Premature failure of these specimens was believed to be caused by a lack of fibers at the failure plane (an effect of the stochastic fiber distribution). Therefore, treating these two specimens as outliers, mean flexural strength was recalculated to be $24 \mathrm{MPa}$, with a standard deviation of $1.9 \mathrm{MPa}$ and a $\mathrm{CoV}$ of $8 \%$.

From posttest inspection of the failure surface, it was observed that all fibers protruding from the failure plane were intact. This indicated that failure of the specimen occurred within the matrix surrounding the fibers, as 
compared with rupture of the fibers themselves. It was also noted that, in general, the fibers at the failure surface had generally retained their hooked ends rather than being straightened. Therefore, the fibers were not simply pulled out of the matrix, which would have resulted in straightening of the hooked ends. Rather, the matrix material appeared to fracture around the fibers during failure, allowing the fibers to retain their hooked ends. The failure surface for specimen F9 is shown in Figure 19.

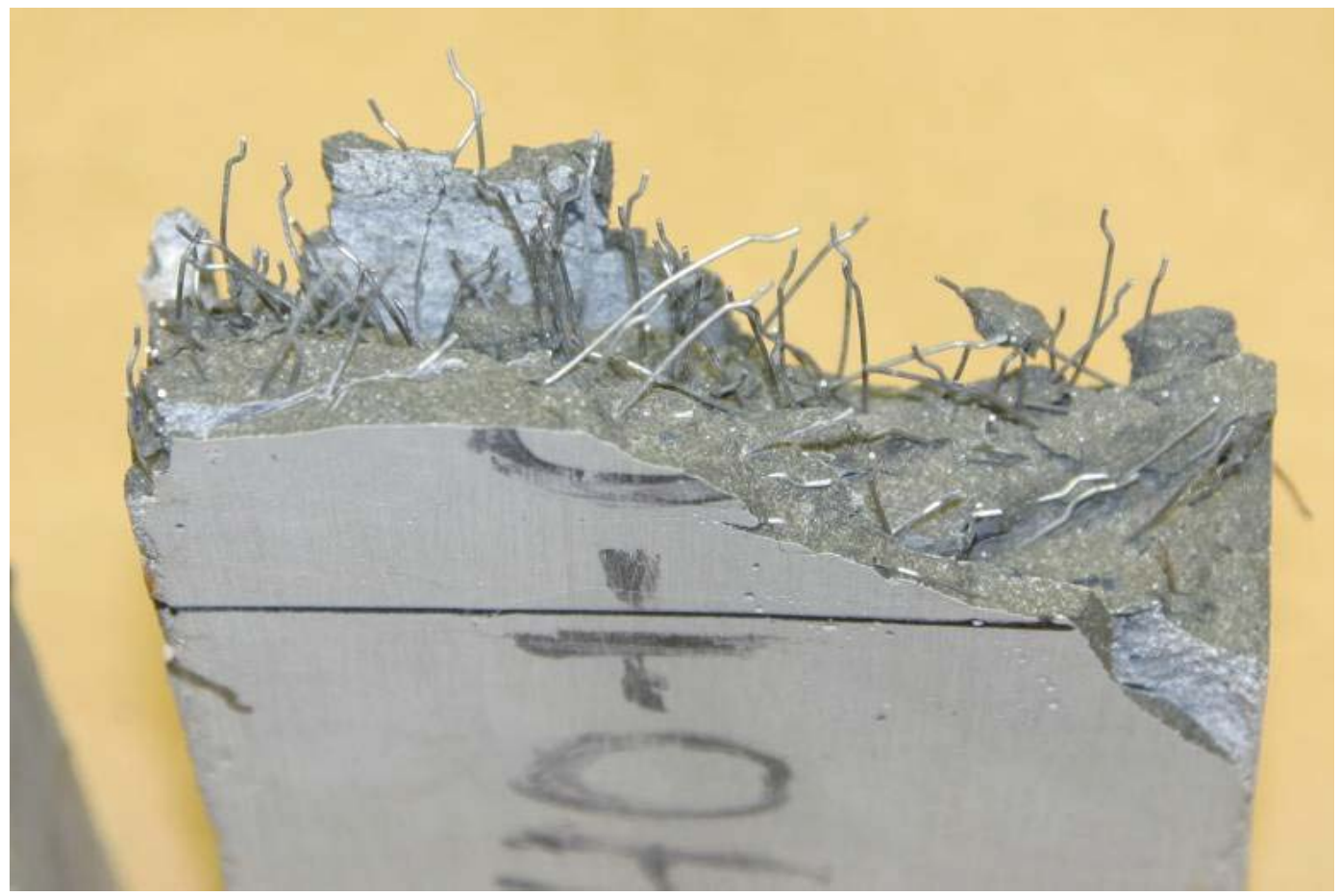

Figure 19. Specimen F9 failure surface.

To directly evaluate the fibers' effect on material strength and ductility, comparison of the 25-mm beams from series 1 (without fibers) and series 3 (with fibers) is given in Figure 20. In the figure, all data sets from series 3 are plotted against the data for specimen NF-5 (series 1), which were selected as a representative sample of the unreinforced specimens.

From comparison of the data in Figure 20, it is observed that initial response of the reinforced and unreinforced material was very similar. Both responses were fairly linear to a load of approximately $4000 \mathrm{~N}$ and generally exhibited a uniform initial material stiffness. Beyond this load, the fibers' influence is clearly observed. Although the unreinforced material immediately failed as a result of the fibers, the reinforced specimens continued to carry load (with the exception of specimens F1 and F8), providing an approximate $45 \%$ increase in load carrying capacity. The 
reinforced specimens also exhibited significantly greater ductility in centerline displacement as compared with the unreinforced material, with an approximate $6 \times$ increase in displacement at peak load and between one and two onders of magnitude increase in displacement at ultimate failure. From Figure 20, it is also noted that the peak load for specimens F1 and F8 approximately corresponded to the maximum load for the unreinforced material. This generally supports the assumption that the weaker responses of specimens F1 and F8 were a result of nonuniform fiber dispersion in the material and an associated reduction of fibers at the failure location.

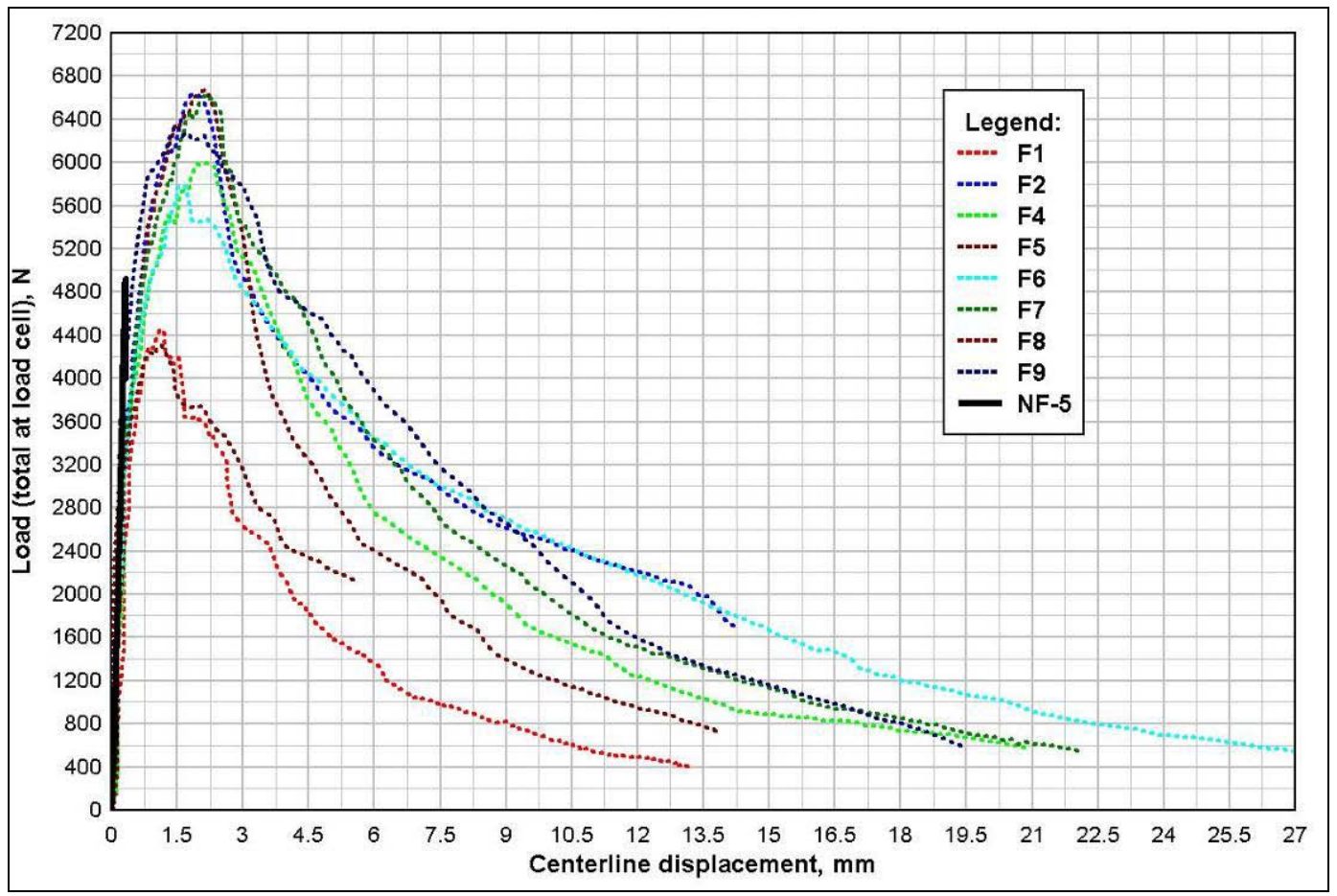

Figure 20. The 25-mm beam load-displacement response, comparison of beams with and without fibers.

The failed specimens from experimental series 3 are shown in Figure 21.

\section{Experimental series 4}

Experimental series 4 was conducted utilizing 356- $\mathrm{mm} \times 102-\mathrm{mm}$ $\times 102$-mm beam samples with reinforcement, thus providing a measure of the reinforced material's flexural characteristics for comparison to the unreinforced data. From Table 4, the mean unconfined compressive strength of the specimens (batch 3) was $188 \mathrm{MPa}$. 


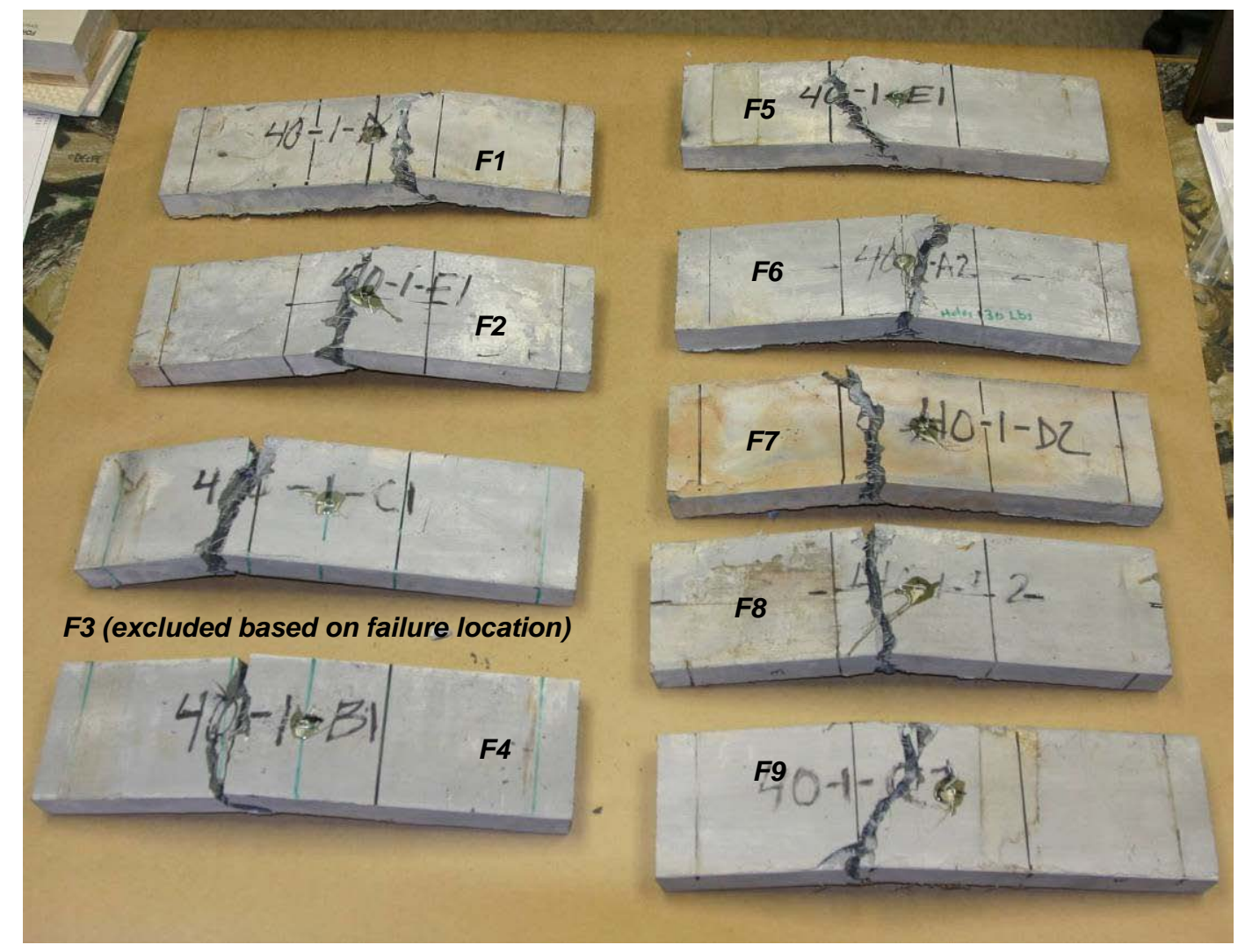

Figure 21. Failed flexural test specimens, $25-\mathrm{mm}$ beams with fibers.

Six tests were conducted in this series; however, one of the specimens (F13) failed outside of the loading points, and the data were discarded. Test results, in terms of total applied load versus centerline displacement, are shown in Figure 22.

As seen from the data, response of the 102-mm beams with fibers was similar to the 25-mm reinforced beams' response. The initial response was relatively linear and uniform, which was followed by a nonlinear response to peak load, and then a softening response until failure. As with the 25- $\mathrm{mm}$ beams, the response following initial linear behavior exhibited reasonable variability, which was attributed to the combined effects of nonuniform reinforcement conditions and hinge formation during failure of the sample (reference discussion for experimental series 3). During the initial response phase, some bilinearity was observed as a result of the seating effect previously discussed. This considered, the data in Figure 22 were adjusted for the seating effect in the same manner as done for series 2 . From comparison of the experimental data to the numerical solutions for the 102-mm beams, it was observed that the initial stiffness was reasonably approximated with a Young's modulus value of $34.5 \mathrm{GPa}$. 


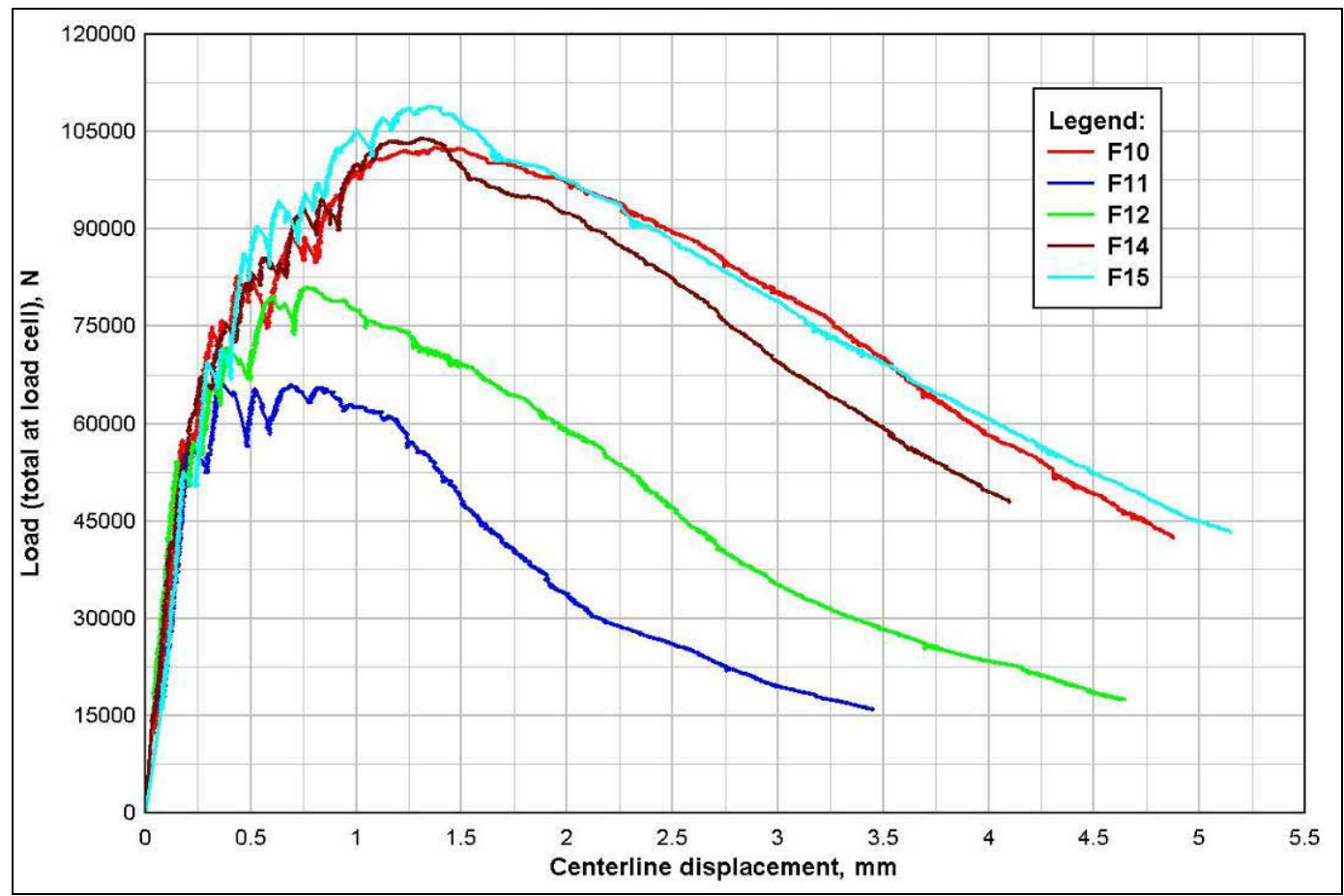

Figure 22. Load-displacement response, 102-mm beams with fibers.

From the data in Figure 22, it was observed that between the initial linear response phase and peak load, the specimens experienced a series of incremental load increases and decreases, observed as the "jagged" response between displacements of approximately $0.25 \mathrm{~mm}$ and $1.25 \mathrm{~mm}$. This was a result of the progressive failure of fiber reinforcement in the material as the fracture progressed through the specimens' cross section. Accordingly, the first drop in load corresponded with the onset of cracking in the cementitious matrix and initial engagement of the fibers. Note that this progressive failure was not observed in the data from series 3 due to a lack of sufficient sensitivity of the string potentiometer used (reference discussion in Chapter 2); however, in reality, the series 3 specimens likely responded in similar fashion.

Flexural strength of the material was determined from the data utilizing equation 2. Based on peak load from each experiment, mean flexural strength was calculated to be $26 \mathrm{MPa}$, with a standard deviation of 5.3 MPa and a CoV of $20 \%$. From the data, it was observed that two specimens (F11 and F12) failed at significantly lower loads than the others. Therefore, treating these specimens as outlier data points, mean flexural strength was recalculated to be $29.6 \mathrm{MPa}$, with a standard deviation of $0.8 \mathrm{MPa}$ and a $\mathrm{CoV}$ of $2.8 \%$. 
Observations of the failure surface were similar to those made for the 25-mm beams. As with the 25-mm beams, failure was due to fiber pullout. In general, it was observed that all fibers were intact and were pulled from the matrix without rupture. However, dissimilar to the 25-mm beams, a portion of the fibers were straightened, while some fibers retained their hooked ends. The failure surface for specimen F15 is shown in Figure 23.

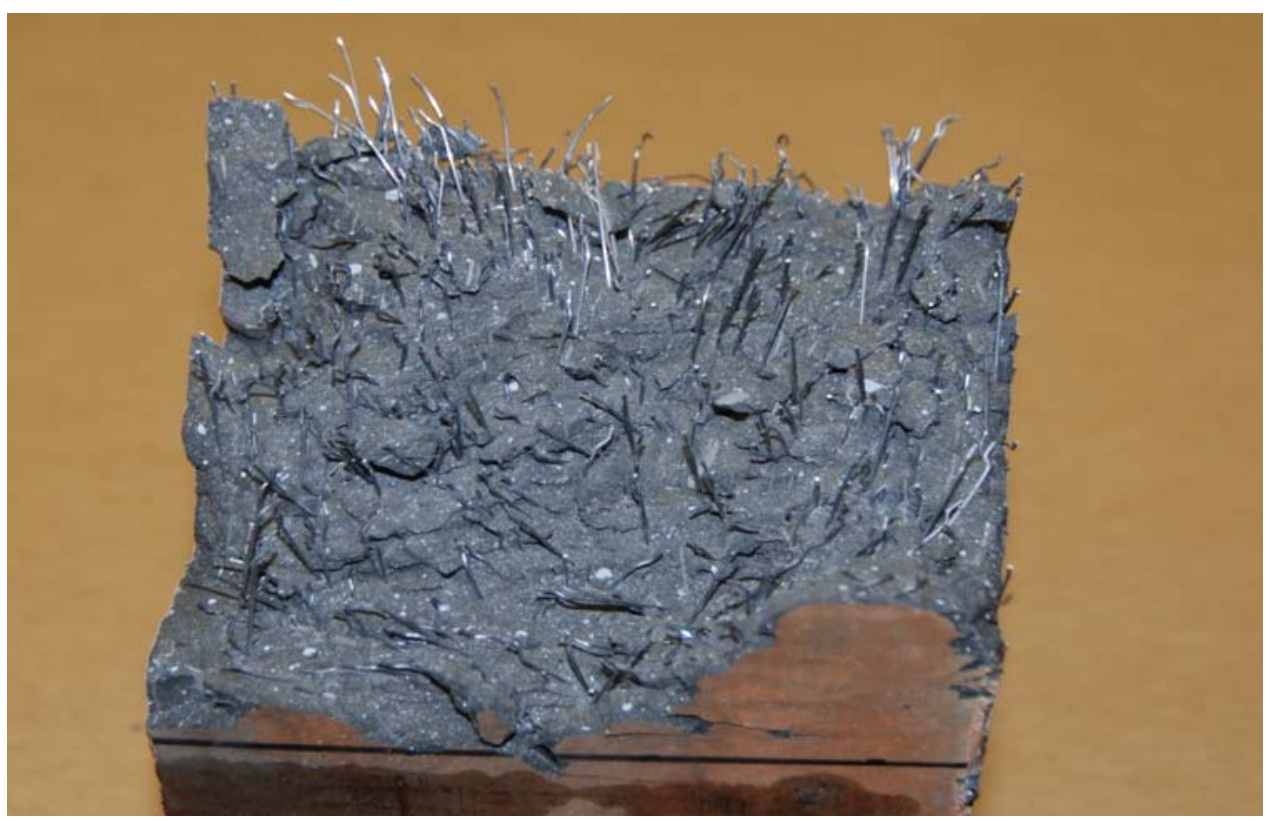

Figure 23. Specimen F15 failure surface.

To directly evaluate the fibers' influence on material strength and ductility, comparison of the 102-mm beams from series 2 (without fibers) and series 4 (with fibers) is given in Figure 24. In the figure, all data sets from series 4 are plotted against the data for specimen NF-12 (series 2), which were selected as a representative sample of the unreinforced specimens.

As with the 25-mm beams, initial linear response of the reinforced and unreinforced 102-mm beams was similar. Notably, failure of the unreinforced specimens generally coincided with the first drop in load in the reinforced specimens, supporting the conclusion that the first load drop corresponded with the onset of matrix cracking. Comparison of the data in Figure 24 also indicated that the fiber reinforcement strongly influenced material strength and ductility, as was expected. With regard to material strength, peak load capacity was increased by approximately $92 \%$ in the reinforced material. The reinforced specimens also exhibited significantly greater ductility in centerline displacement as compared with the unreinforced material, with an approximate $3 \times$ increase in displacement at peakload. 


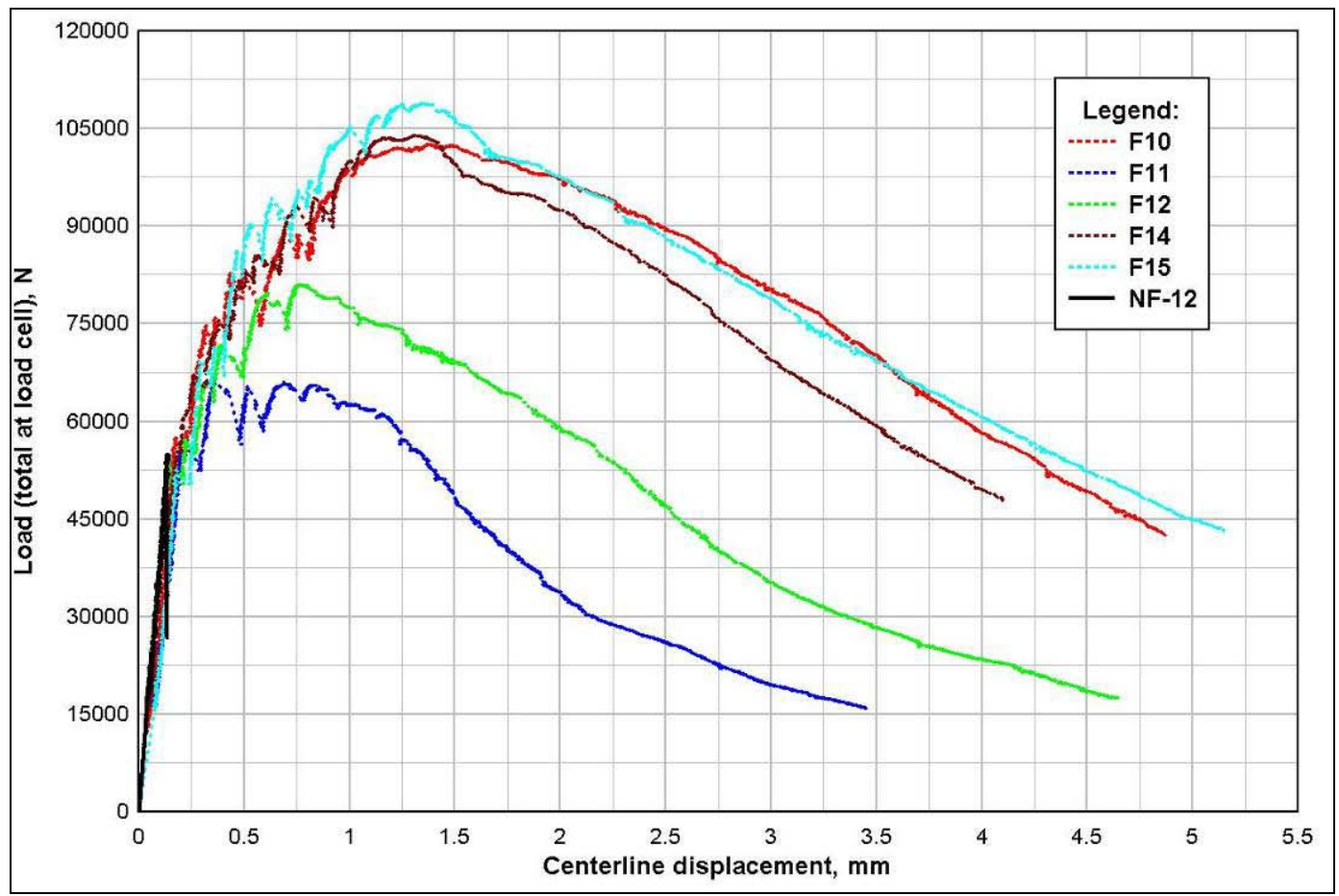

Figure 24. 102-mm beam load-displacement response, comparison of beams with and without fibers.

The failed specimens from experimental series 4 are shown in Figure 25.

\section{Experimental series 5}

Experimental series 5 was conducted utilizing 1,016-mm $\times 102-\mathrm{mm}$ $\times 102-\mathrm{mm}$ beam samples. Fiber reinforcement was provided in the beams, and the span was tripled (to $914 \mathrm{~mm}$ ) over that used in series 4 . As a result, the aspect ratio (span:depth) of the specimens in series 5 was approximately 9, as compared with an aspect ratio of 3 in series 4 . From Table 4, the mean unconfined compressive strength of specimens F16, F17, and F18 (batch 3) was $188 \mathrm{MPa}$, and the mean strength of specimens F19, F20, and F21 (batch 4) was $194 \mathrm{MPa}$.

Six tests were conducted in this series; however, data from one of the tests (F16) were lost due to failure of the data acquisition system. Results for the remaining five tests, in terms of total applied load versus centerline displacement, are shown in Figure 26. Also given in Figure 26 are closedform displacement solutions utilizing equation 1 and assumed $E$ values of 34.5 GPa and $38 \mathrm{GPa}$. 


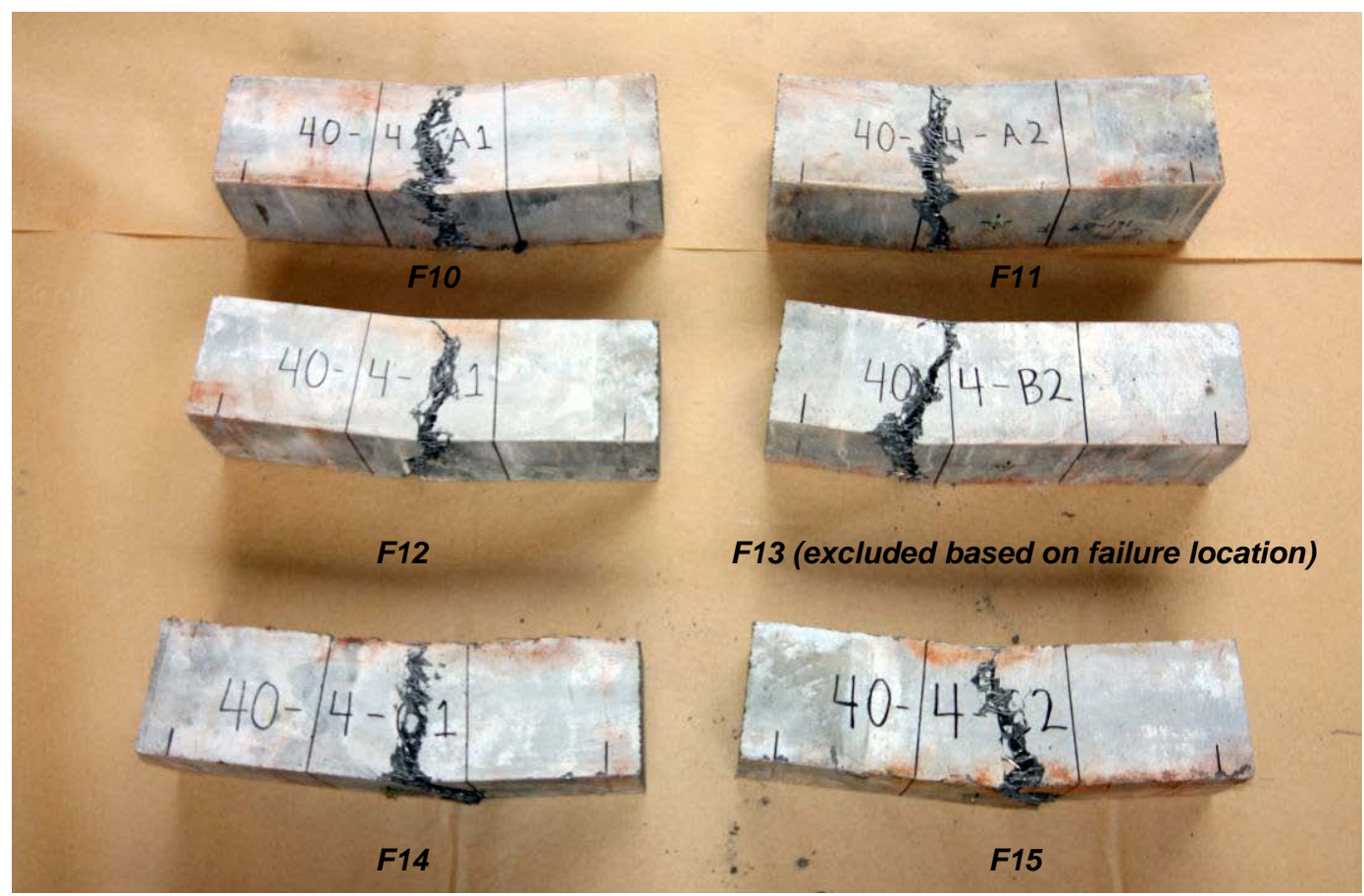

Figure 25. Failed flexural test specimens, 102-mm beams with fibers.

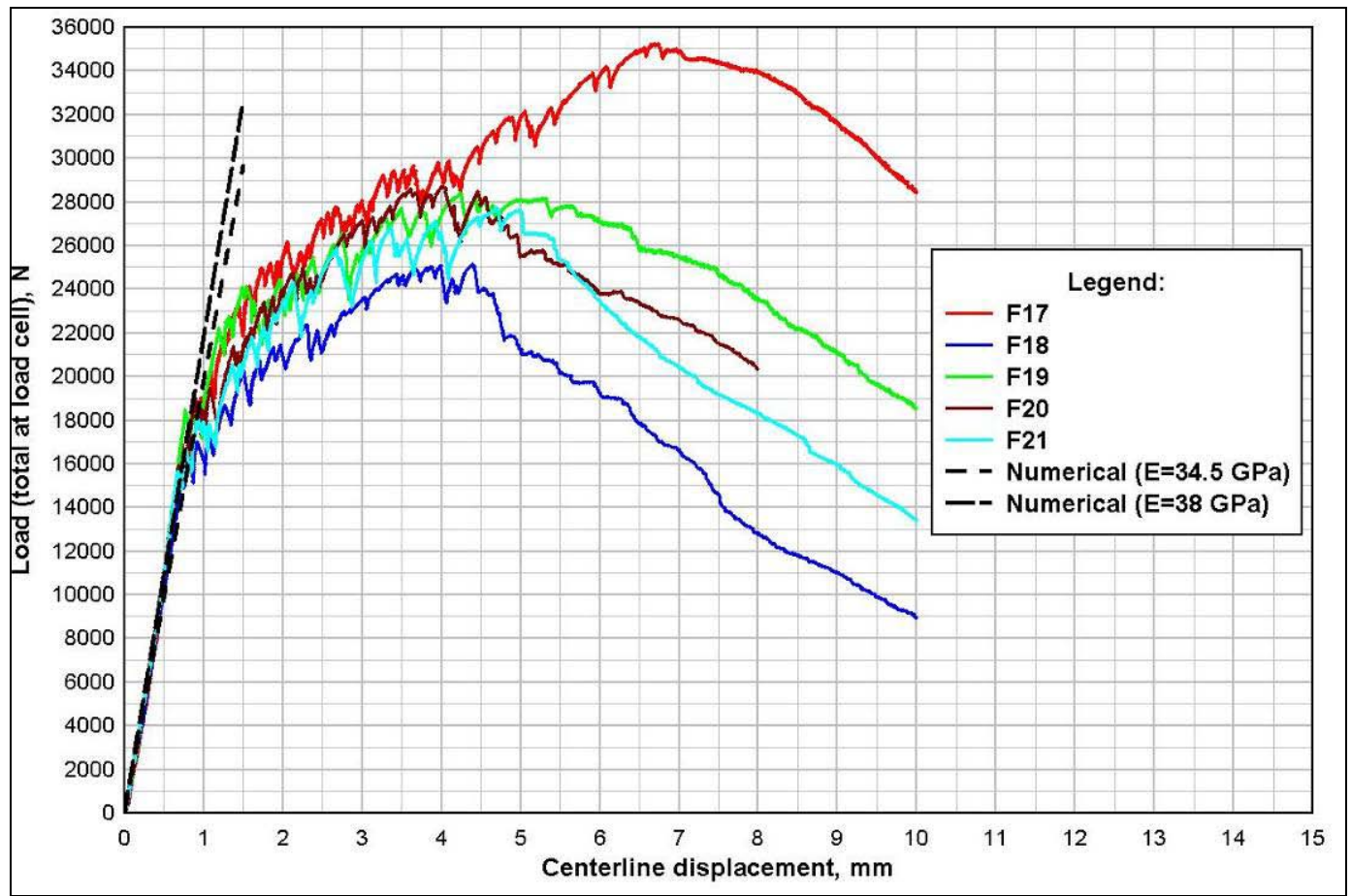

Figure 26. Load-displacement response, 1016-mm beams with fibers.

As seen, response of the beams in series 5 was similar to that observed for the other reinforced beams, i.e., series 3 and 4 . The initial response was relatively linear and uniform until cracking was initiated in the cementitious matrix. The response was then nonlinear until peak load and was 
characterized by incremental loading/ unloading cycles as a result of the progressive failure of the fiber reinforcement. After peak load, the material exhibited a softening response, which would continue until ultimate failure occurred. Note that, for series 5, the tests were not conducted until complete failure due to testing time constraints. Rather, with the exception of F20, testing was terminated once the centerline displacement reached $10 \mathrm{~mm}$. Test F20 was terminated when displacement reached $8 \mathrm{~mm}$. From the initial linear response data, a mean Young's modulus value of $32.9 \mathrm{GPa}$ was calculated, with a standard deviation of $1.1 \mathrm{GPa}$ and a $\mathrm{CoV}$ of $3 \%$. From comparison to the closed-form solutions, it was seen that the analytically determined initial response closely matched the experimental, indicating that the closed-form solution was applicable for the given span:depth aspect ratio.

Based on peak load from each experiment, mean flexural strength was calculated to be $23.9 \mathrm{MPa}$, with a standard deviation of $2.7 \mathrm{MPa}$ and a $\mathrm{CoV}$ of $11 \%$.

The failed specimens from experimental series 5 are shown in Figure 27.

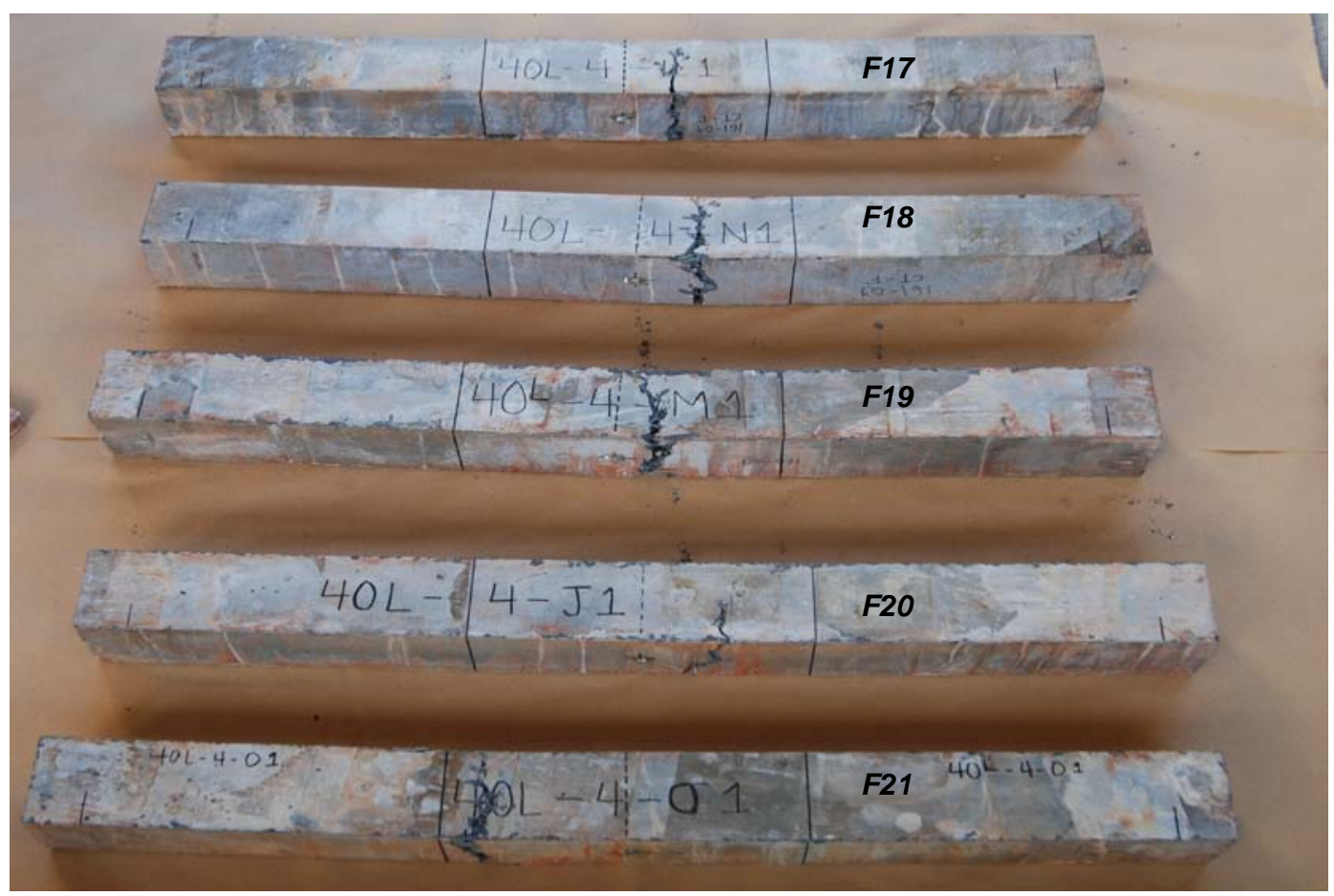

Figure 27. Failed flexural test specimens, 102-mm beams with fibers (1016-mm span). 


\section{Splitting Tensile Test Results}

In addition to the flexural tests presented in Chapter 4, two series of splitting tensile tests were conducted as a part of the experimental program. To quantify the reinforcement fibers' influence on the splitting tensile response, experimental series 6 was conducted with specimens containing fibers, and series 7 was conducted with unreinforced Cor-Tuf material. Six specimens were tested in each series, and the results are summarized in the following sections.

For each series, results are presented in terms of splitting tensile stress versus displacement of the test machine's loading head. In accordance with the ASTM standard, splitting tensile stress in the specimen, $\sigma_{\mathrm{st}}$, was calculated by Equation 3.

$$
\sigma_{\mathrm{st}}=\frac{2 \mathrm{P}_{\mathrm{st}}}{\pi A}
$$

where:

$$
\begin{aligned}
\sigma_{\text {st }}= & \text { splitting tensile stress in the specimen, } \mathrm{MPa} \\
\mathrm{P}_{\mathrm{st}}= & \text { load applied during the splitting tensile test, } \mathrm{N} \\
\mathrm{A}= & \text { cross sectional area of the specimen (on a plane perpendicular } \\
& \text { to splitting tensile stress), } \mathrm{mm}^{2} .
\end{aligned}
$$

\section{Experimental series 6}

Experimental series 6 was conducted utilizing 102-mm $\times$ 204-mm test cylinders with reinforcement, thus providing a measure of the splitting tensile strength of the reinforced Cor-Tuf material. From Table 4, the mean unconfined compressive strength of the test specimens was 204 MPa from batch 5.

Test results, in terms of splitting tensile stress versus the loading head displacement, are shown in Figure 28. 


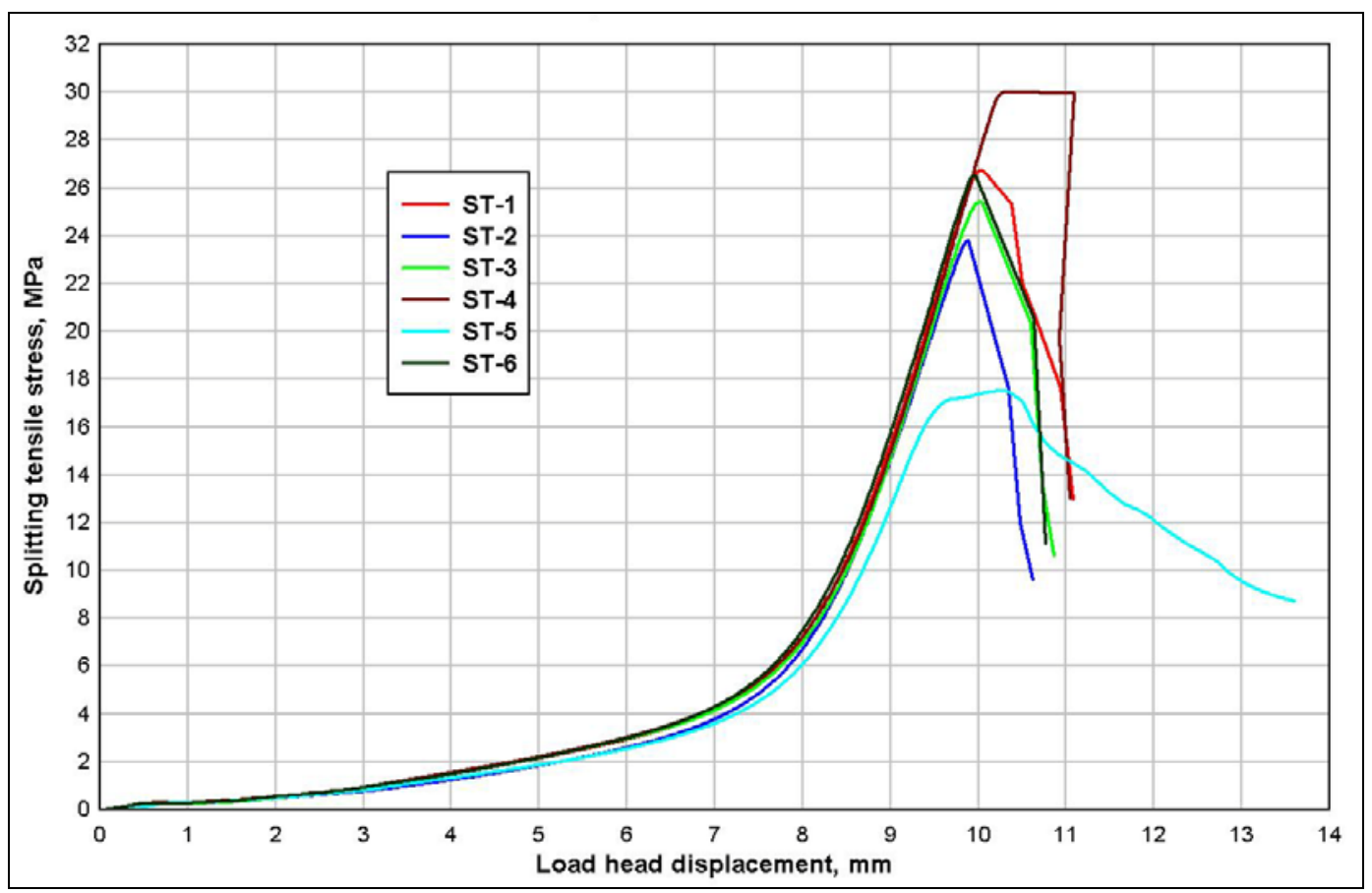

Figure 28. Splitting tensile response, fiber reinforced specimens.

As seen from the data, response of the specimens was generally uniform, with moderate variability observed in terms of the splitting tensile strength at failure. From the data, the mean splitting tensile strength was calculated to be $25.0 \mathrm{MPa}$, with a standard deviation of $4.2 \mathrm{MPa}$ and a CoV of $16.8 \%$. Considering the results from ST- 4 and ST- 5 as outlier data points, splitting tensile strength was recalculated to be $25.6 \mathrm{MPa}$, with a standard deviation of $1.4 \mathrm{MPa}$ and a $\mathrm{CoV}$ of $5.5 \%$. Because of the balanced nature of tests ST-4 and ST-5, the recalculation did not significantly alter the mean strength value; however, the standard deviation and $\mathrm{CoV}$ were significantly reduced.

A failed splitting tensile test sample from series 6 is shown in Figure 29.

\section{Experimental series 7}

Experimental series 7 was conducted utilizing $102-\mathrm{mm} \times 204-\mathrm{mm}$ test cylinders without reinforcement, thus providing a measure of the splitting tensile strength of the plain Cor-Tuf material. From Table 4, the mean unconfined compressive strength of the test specimens was $182 \mathrm{MPa}$ from batch 6 .

Test results, in terms of splitting tensile stress versus the loading head displacement, are shown in Figure 30. 


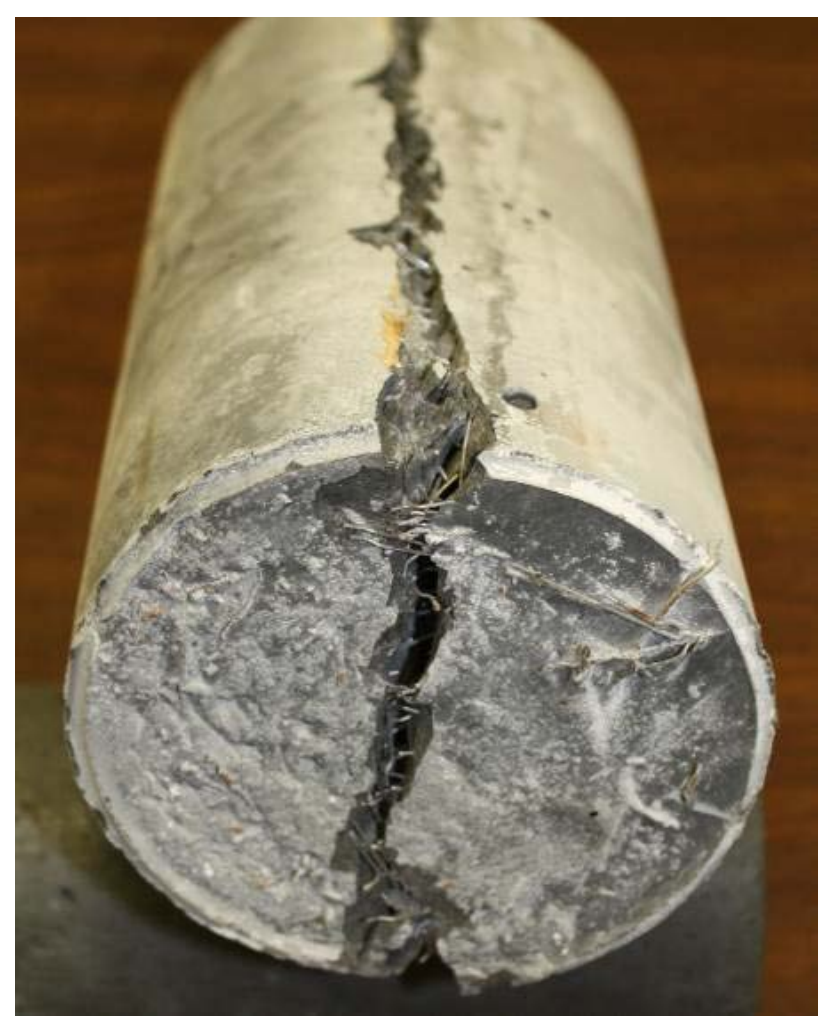

Figure 29. Cor-Tuf specimen failed in splitting tensile mode.

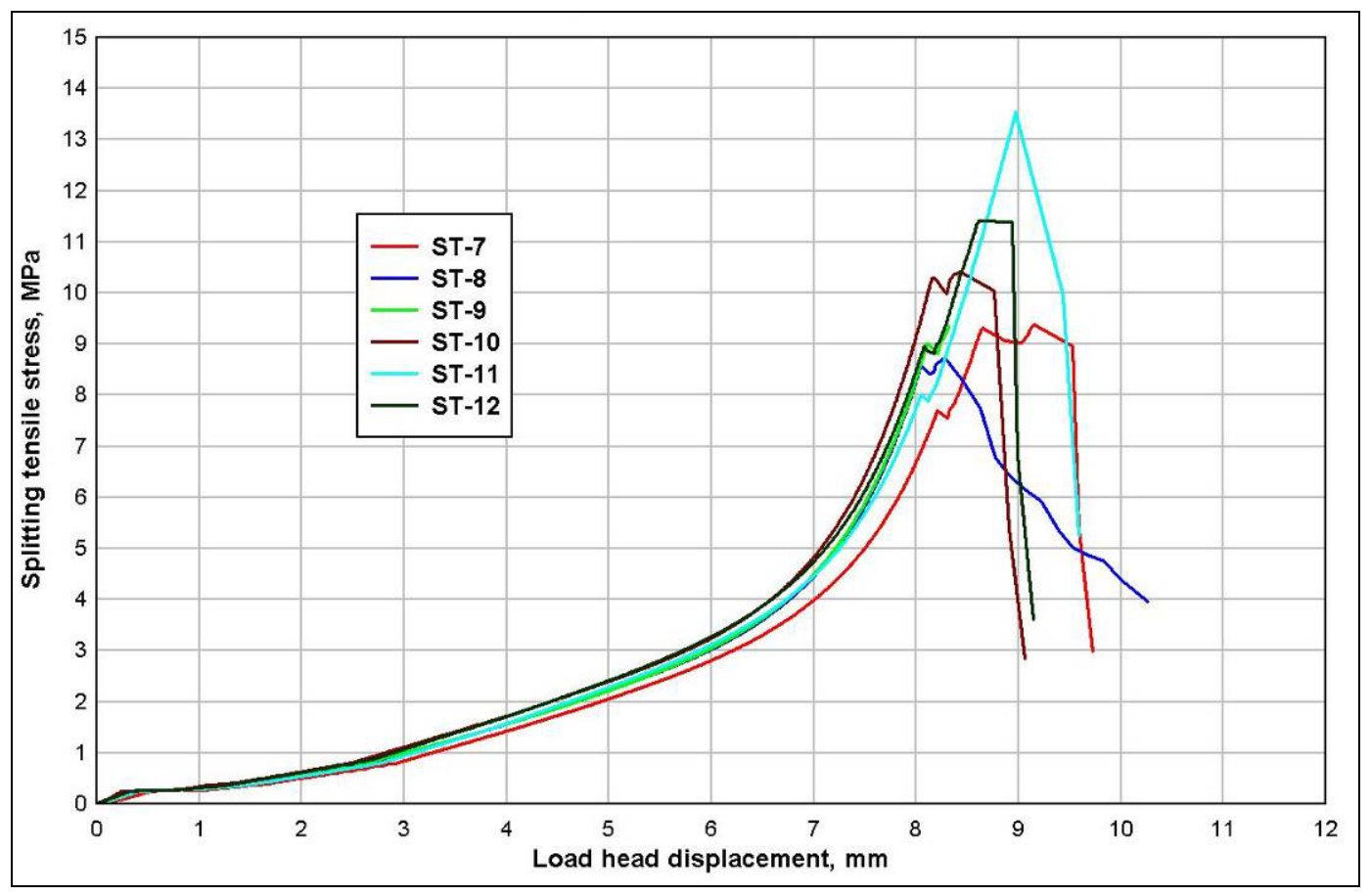

Figure 30 . Splitting tensile response, unreinforced specimens. 
Response of the unreinforced specimens was similar to that of the reinforced material in series 6, although greater variability in the failure response was observed in the unreinforced material. In general, failure response of the unreinforced material was characterized by a small initial load drop, which was followed by one or two loading/ unloading cycles until complete failure occurred. From the data, mean splitting tensile strength of the unreinforced material was calculated to be 10.4 MPa, with a standard deviation of $1.8 \mathrm{MPa}$ and a $\mathrm{CoV}$ of $17 \%$. Considering the results from specimen ST-11 as outlier data, the mean strength was recalculated to be $9.8 \mathrm{MPa}$, with a standard deviation of $1.1 \mathrm{MPa}$ and a $\mathrm{CoV}$ of $11 \%$.

To provide a direct comparison between the splitting tensile response of the reinforced and unreinforced material, results from series 6 are plotted against specimen ST-10 in Figure 31 (ST-10 selected as a representative specimen from series 7). As seen, the unreinforced material generally responded in the same manner as the reinforced but simply failed at a lower tensile stress.

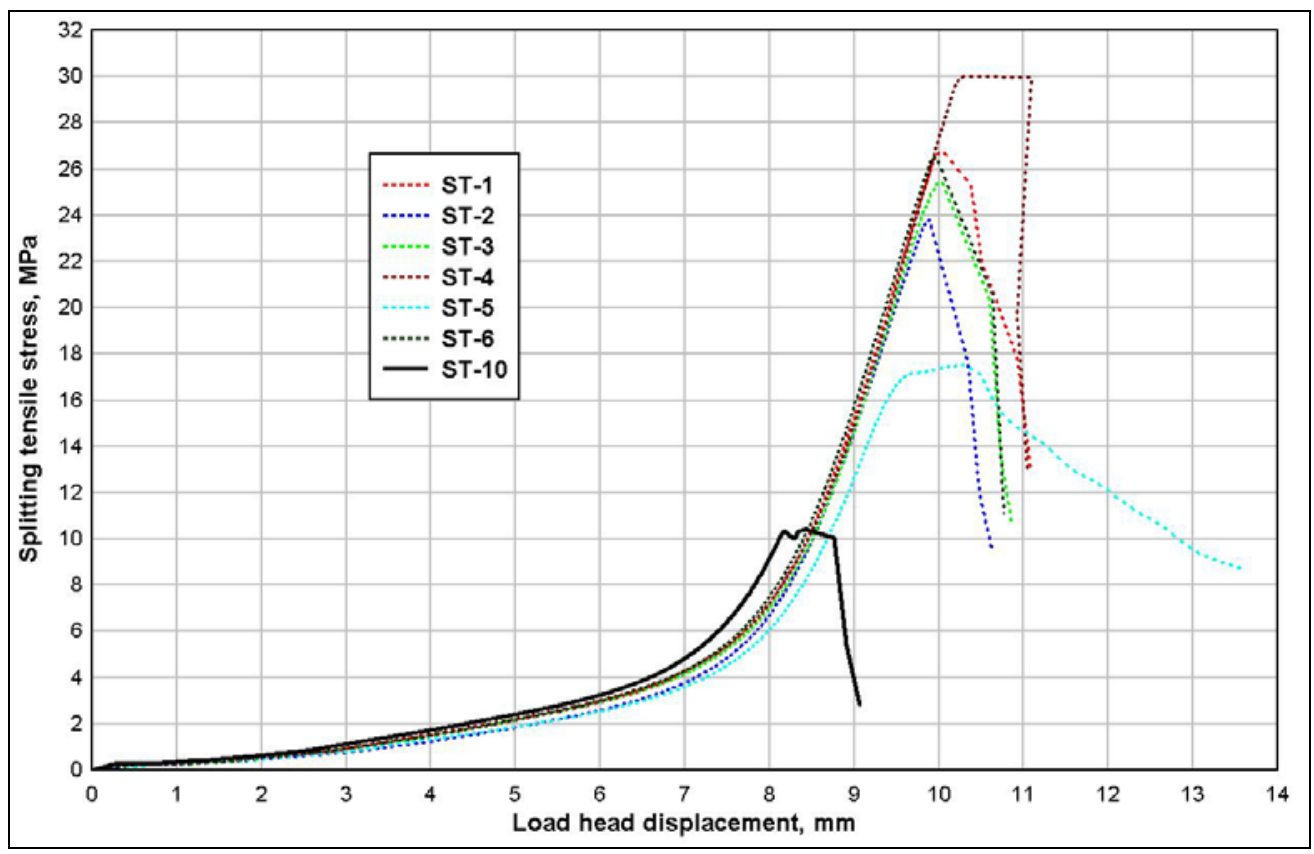

Figure 31. Splitting tensile response, comparison of reinforced and unreinforced results. 


\section{Summary and Conclusions}

The objective of this experimental program was to determine flexural and splitting tensile properties of the Cor-Tuf ultra high-strength concrete material. Material specimens were tested with and without randomly distributed steel fiber reinforcement, providing a measure of the reinforced and unreinforced material properties. As a part of the program, 33 flexural tests and 12 splitting tensile tests were conducted in accordance with the requirements of ASTM standards C1609 and C496, respectively. In addition to varying the reinforcement conditions, as a part of the flexural test series, the beams' size and span were also varied to gauge their effect on the experimental results. In conjunction with the flexural and tensile testing, unconfined compression tests were performed to verify material quality and consistency between the specimen production batches.

Prior to conducting the Cor-Tuf flexural experiments, two control tests were conducted with steel members to evaluate the experimental setup. The first control test was conducted with a 6-mm-thick steel plate, and the measured centerline displacement nearly exactly matched the closed-form displacement solution for the given boundary conditions. However, the second control test was conducted with a 102-mm hollow structural steel tube, and results showed that the measured stiffness (measured in terms of centerline displacement) was much lower than the closed-form prediction.

Based on observations from the steel member control tests, two finite element analyses were performed to further investigate initial linear-elastic response of the thinner and thicker beams, as well as to consider applicability of the closed-form displacement solution for each case. The first FE analysis was conducted with a 25-mm-thick beam (to match the thin Cor-Tuf beam specimens), and the second was conducted with a 102-mm-thick beam (to match the thick Cor-Tuf beam specimens). Results of both analyses were compared with closed-form solutions for centerline displacement, and it was found that for the thin-beam case, the numerical and closed-form solutions were in near-exact agreement. However, for the thick-beam case, the closed-form and numerical solutions diverged, exhibiting the same trend as observed in the control tests (i.e., numerical solution was significantly softer than the closed-form). The suspected cause 
of this disagreement was excessive shear deformation in the thick beams, which was not considered in the closed-form solution (since it was based on an Euler-Bernoulli beam formulation). As a result, the closed-form expression was determined to be inapplicable for calculation of the thick beams' displacement response and any displacement-based material properties, such as Young's modulus.

A primary property of interest from the four-point bending tests was the Cor-Tuf material's reinforced and unreinforced flexural strength. Flexural strength results from the bending tests (experimental series 1 through 5) are summarized in Table 5 below. As noted in discussions of the experimental results, many of the data sets appeared to contain outlier data points; subsequently, flexural strength was calculated with and without consideration of these data. Consequently, in Table 5, the mean strength, standard deviation, and $\mathrm{CoV}$ are given for both conditions. Also given in Table 5 are the mean unconfined compressive strengths associated with each series.

Table 5. Flexural tests, flexural strength summary.

\begin{tabular}{|c|c|c|c|c|c|c|c|c|}
\hline \multirow[b]{2}{*}{ Series } & \multirow[b]{2}{*}{ Fibers } & \multirow[b]{2}{*}{$\mathrm{f}_{\mathrm{c}^{1,4}}, \mathrm{MPa}$} & \multicolumn{3}{|c|}{ Outliers Included } & \multicolumn{3}{|c|}{ Outliers Excluded } \\
\hline & & & $\sigma^{2}, \mathrm{MPa}$ & $\sigma_{d^{3}}, \mathrm{MPa}$ & CoV, \% & $\sigma, \mathrm{MPa}$ & $\sigma_{\mathrm{d}}, \mathrm{MPa}$ & CoV, \% \\
\hline 1 & without & 183 & 14.5 & 3.1 & 21 & 16.6 & 1.1 & 6 \\
\hline 2 & without & 183 & 13.7 & 3.8 & 27.6 & 15.3 & 0.8 & 5 \\
\hline 3 & with & 175 & 22 & 3.9 & 17.5 & 24 & 1.9 & 8 \\
\hline 4 & with & 188 & 26 & 5.3 & 20 & 29.6 & 0.8 & 2.8 \\
\hline 5 & with & $188 / 194$ & 23.9 & 2.7 & 11 & - & - & - \\
\hline \multicolumn{9}{|c|}{$\begin{array}{l}{ }^{1} \mathrm{f}_{\mathrm{c}}^{\prime}=\text { mean unconfined compressive strength. } \\
{ }^{2} \sigma=\text { mean flexural strength from each series. } \\
{ }^{3} \sigma_{d}=\text { standard deviation. }\end{array}$} \\
\hline
\end{tabular}

As reported in Table 5, the unconfined compressive strength values ranged from $175 \mathrm{MPa}$ to $194 \mathrm{MPa}$. Taking all five test series together, the overall mean was $185 \mathrm{MPa}$, the standard deviation was $6 \mathrm{MPa}$, and the CoV was $3.5 \%$. The low $\mathrm{CoV}$ demonstrates consistent material quality with respect to all experimental series.

Table 5 presents flexural strength results for the complete data set from each experimental series, as well as for each data set with outliers 
excluded. In each case, the exclusion of outliers yields a somewhat greater mean flexural strength, about $12 \%$ greater on average. The fact that the outliers tend toward lower strength values is expected. The beams should break in the areas where their cross-sections are the weakest. The weak areas are thought to correspond to flaws or defects. If a beam has a particularly severe flaw or imperfection in the high stress area, it is thought that the beam will break at the flaw, thus resulting in an outlier value that is less than the mean. It is considered unlikely that a flaw or defect in a specimen would result in an unusually high strength value. Thus, the exclusion of outliers is considered acceptable as it accounts for especially imperfect specimens.

Excluding outliers, the mean flexural strengths of the unreinforced and fiber-reinforced materials were 16 and $25 \mathrm{MPa}$, respectively. These data suggest that the fiber-reinforcement significantly influenced the flexural strength of material, providing an approximate $162 \%$ increase in the material strength. It does not appear that the aspect ratio (span:depth) had a significant effect on the flexural strength values. In the unreinforced case, the larger aspect ratio (12:1) specimens had slightly higher flexural strengths, while the opposite was observed for the reinforced case (i.e., the 12:4 or 3:1 specimens were slightly stronger on average).

Young's modulus was also estimated for each of the flexural test series. Mean E values from each series are summarized in Table 6. As seen, the moduli values ranged from $32.9 \mathrm{GPa}$ to $38.3 \mathrm{GPa}$. The mean of all test series was $34.8 \mathrm{GPa}$, with a standard deviation of $2.1 \mathrm{GPa}$ and a $\mathrm{CoV}$ of $6 \%$.

Table 6. Flexural tests, Young's modulus summary.

\begin{tabular}{|l|l|l|l|l|}
\hline Series & Fibers & $E, \mathrm{GPa}$ & $\sigma_{\mathrm{d}}, \mathrm{GPa}$ & $\mathrm{CoV}, \%$ \\
\hline 1 & without & 38.3 & 2.6 & 7 \\
\hline 2 & without & 34.5 & - & - \\
\hline 3 & with & 33.8 & - & - \\
\hline 4 & with & 34.5 & - & - \\
\hline 5 & with & 32.9 & 1.1 & 3 \\
\hline
\end{tabular}

After completion of the flexural testing, the failure plane for several of the reinforced specimens was studied to investigate the fiber reinforcement's failure mechanisms. From posttest observations, it appeared that little or no fiber rupture occurred during the failure process. Rather, all fibers were 
pulled from the matrix material in some form. In the case of the 25- $\mathrm{mm}$ beams, the fibers did not appear to have been pulled from the matrix, because most of the hooked ends had not been straightened. Instead, the matrix appeared to have failed around the fibers, leaving the hooked ends intact. Similar observations were also made for the 102-mm beams, where a significant number of fibers retained their hooked ends after the failure process. However, it was also observed that some fibers were also straightened, indicating that they had been pulled from the matrix in a more typical pullout failure mode.

Similar to determination of flexural strength, in series 6 and 7, the splitting tensile strength was calculated with and without outlier data points considered. A summary of the splitting tensile strength values is given in Table 7. As seen, the mean strengths did not change significantly based on consideration of the full or partial data sets. From the data, mean splitting tensile strength for the fiber reinforced material was $25.0 \mathrm{MPa}$, and mean strength for the unreinforced material was 10.4 MPa. Based on this data, the fibers significantly influenced splitting tensile strength of the material, providing an approximate $240 \%$ increase in the material strength.

Table 7. Splitting tensile tests, Splitting tensile strength summary.

\begin{tabular}{|c|c|c|c|c|c|c|c|c|}
\hline \multirow[b]{2}{*}{ Series } & \multirow[b]{2}{*}{ Fibers } & \multirow[b]{2}{*}{$\mathrm{f}_{\mathrm{c}^{1}}, \mathrm{MPa}$} & \multicolumn{3}{|c|}{ Outliers Included } & \multicolumn{3}{|c|}{ Outliers Excluded } \\
\hline & & & $\sigma_{\mathrm{st}^{2}}{ }^{2}, \mathrm{MPa}$ & $\sigma_{d}^{3}, \mathrm{MPa}$ & CoV, \% & $\sigma_{\mathrm{st}}, \mathrm{MPa}$ & $\sigma_{\mathrm{d}}, \mathrm{MPa}$ & CoV, \% \\
\hline 6 & with & 204 & 25 & 4.2 & 17 & 25.6 & 1.4 & 5.5 \\
\hline 7 & without & 182 & 10.4 & 1.8 & 17 & 9.8 & 1.1 & 11 \\
\hline $\begin{array}{l}{ }^{1} f_{c}^{\prime}=n \\
{ }^{2} \sigma_{s t}=r \\
{ }^{3} \sigma_{d}=s\end{array}$ & $\begin{array}{l}\text { nean uncc } \\
\text { mean spli } \\
\text { tandard c }\end{array}$ & $\begin{array}{l}\text { fined comr } \\
\text { ng tensile } \\
\text { viation. }\end{array}$ & $\begin{array}{l}\text { ressive stre } \\
\text { trength fro }\end{array}$ & $\begin{array}{l}\text { sth. } \\
\text { each serie }\end{array}$ & & & & \\
\hline
\end{tabular}




\section{References}

ABAQUS/ CAE, Version 6.5-4. 2005. Providence, RI: SIMULIA.

American Society for Testing and Materials. 2005. Annual book of ASTM standards. Philadelphia, PA.

a. Designation C 39-05. Standard test method for compressive strength of concrete specimens.

b. Designation C 109-08. Standard test method for compressive strength of hydraulic cement mortars (using 2-in. or [50-mm] cube specimens).

c. Designation C 496- 04. Standard test method for splitting tensile strength of cylindrical concrete specimens.

d. Designation C 1609-07. Standard test method for flexural performance of fiber-reinforced concrete (using beam with third-point loading).

Williams, E.M., Graham, S.S., Reed, P.A. and Rushing, T.S. 2009. Laboratory characterization of Cor-Tuf concrete with and without steel fibers. ERDC/GSL TR-09-22. Vicksburg, MS: U.S. Army Engineer Research and Development Center. 


\section{Appendix A: Beam Specimen Dimensions}

Table A1. Beam specimen cross section dimensions, Series 1.

\begin{tabular}{|l|l|l|l|}
\hline Specimen No. & Width, $\mathrm{mm}$ & Depth, $\mathrm{mm}$ & Moment of Inertia, $\mathrm{mm}^{4}$ \\
\hline NF-1 & 99.4 & 28.4 & 190,199 \\
\hline NF-2 & 99.8 & 28.6 & 194,768 \\
\hline NF-3 & 101.1 & 28.3 & 190,364 \\
\hline NF-4 & 99.9 & 28.4 & 191,379 \\
\hline NF-5 & 99.6 & 29.7 & 217,574 \\
\hline NF-6 & 99.3 & 28.7 & 195,974 \\
\hline Mean & 99.8 & 28.7 & 196,710 \\
\hline$\sigma_{d}$ & 0.6 & 0.5 & 9,580 \\
\hline CoV, percent & 0.6 & 2 & 5 \\
\hline
\end{tabular}

Table A2. Beam specimen cross section dimensions, Series 2.

\begin{tabular}{|l|l|l|l|}
\hline Specimen No. & Width, $\mathrm{mm}$ & Depth, $\mathrm{mm}$ & Moment of Inertia, $\mathrm{mm}^{4}$ \\
\hline NF-7 & 102.8 & 104.4 & $9,742,181$ \\
\hline NF-8 & 102.5 & 102.0 & $9,053,925$ \\
\hline NF-9 & 101.7 & 103.7 & $9,468,433$ \\
\hline NF-10 & 101.8 & 102.8 & $9,207,897$ \\
\hline NF-11 & 102.3 & 103.3 & $9,410,188$ \\
\hline NF-12 & 101.9 & 103.2 & $9,327,998$ \\
\hline Mean & 102.2 & 103.2 & $9,368,437$ \\
\hline$\sigma_{d}$ & 0.4 & 0.8 & 215,156 \\
\hline CoV, percent & 0.4 & 0.7 & 2 \\
\hline
\end{tabular}


Table A3. Beam specimen cross section dimensions, Series 3.

\begin{tabular}{|l|l|l|l|}
\hline Specimen No. & Width, $\mathrm{mm}$ & Depth, $\mathrm{mm}$ & Moment of Inertia, $\mathrm{mm}^{4}$ \\
\hline F1 & 100.6 & 28.5 & 195,174 \\
\hline F2 & 100.3 & 27.7 & 178,319 \\
\hline F3 & 99.8 & 28.2 & 186,154 \\
\hline F4 & 101.7 & 27.7 & 179,924 \\
\hline F5 & 100.6 & 27.8 & 180,362 \\
\hline F6 & 100.8 & 28.2 & 188,718 \\
\hline F71 & - & - & - \\
\hline F8 & 100.9 & 28.5 & 195,642 \\
\hline F9 & 100.3 & 29.5 & 213,749 \\
\hline Mean & 100.6 & 28.3 & 189,755 \\
\hline Od & 0.5 & 0.6 & 11,008 \\
\hline CoV, percent & 0.5 & 2 & 6 \\
\hline 1 Dimensions not taken for specimen F7 & \\
\hline
\end{tabular}

Table A4. Beam specimen cross section dimensions, Series 4.

\begin{tabular}{|l|l|l|l|}
\hline Specimen No. & Width, $\mathrm{mm}$ & Depth, $\mathrm{mm}$ & Moment of Inertia, $\mathrm{mm}^{4}$ \\
\hline F10 & 104.5 & 102.0 & $9,254,269$ \\
\hline F11 & 105.8 & 102.4 & $9,481,279$ \\
\hline F12 & 104.4 & 102.1 & $9,272,758$ \\
\hline F13 & 104.0 & 102.6 & $9,355,564$ \\
\hline F14 & 101.8 & 102.4 & $9,112,612$ \\
\hline F15 & 102.9 & 103.0 & $9,367,740$ \\
\hline Mean & 103.9 & 102.4 & $9,307,371$ \\
\hline$\sigma_{d}$ & 1.3 & 0.3 & 114,134 \\
\hline CoV, percent & 1.2 & 0.3 & 1.2 \\
\hline
\end{tabular}


Table A5. Beam specimen cross section dimensions, Series 5.

\begin{tabular}{|l|l|l|l|}
\hline Specimen No. & Width, $\mathrm{mm}$ & Depth, $\mathrm{mm}$ & Moment of Inertia, $\mathrm{mm}^{4}$ \\
\hline F16 & 103.7 & 102.1 & $9,205,107$ \\
\hline F17 & 101.8 & 102.9 & $9,242,981$ \\
\hline F18 & 102.3 & 103.6 & $9,472,551$ \\
\hline F19 & 105.6 & 104.1 & $9.925,059$ \\
\hline F20 & 105.4 & 103.6 & $9,781,693$ \\
\hline F21 & 103.9 & 103.0 & $9,453,913$ \\
\hline Mean & 103.8 & 103.2 & $9,513,551$ \\
\hline$\sigma_{d}$ & 1.4 & 0.6 & 262,939 \\
\hline CoV, percent & 1.3 & 0.6 & 2.8 \\
\hline
\end{tabular}




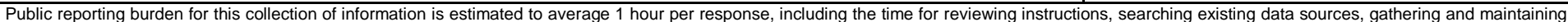

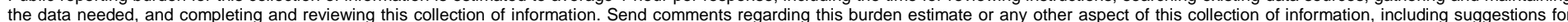

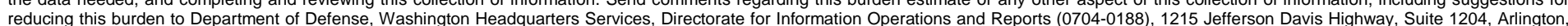

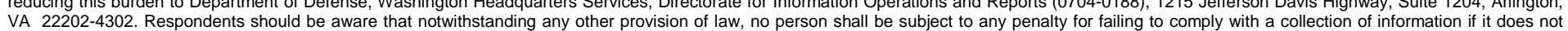
VA 22202-4302. Respondents should be aware that notwithstanding any other provision of law, no person shall be sub
display a currently valid OMB control number. PLEASE DO NOT RETURN YOUR FORM TO THE ABOVE ADDRESS.

\begin{tabular}{l|c}
$\begin{array}{l}\text { 1. REPORT DATE (DD-MM- } Y Y Y Y) \\
\text { October } 2010\end{array}$ & $\begin{array}{c}\text { 2. REPORT TYPE } \\
\text { Final report }\end{array}$ \\
\hline
\end{tabular}

\section{TITLE AND SUBTITLE}

Laboratory Investigation of the Characterization of Cor-Tuf Flexural and Splitting Tensile Properties

3. DATES COVERED (From - To)

5a. CONTRACT NUMBER

5b. GRANT NUMBER

5c. PROGRAM ELEMENT NUMBER

5d. PROJECT NUMBER

5e. TASK NUMBER

5f. WORK UNIT NUMBER

8. PERFORMING ORGANIZATION REPORT NUMBER

ERDC/GSL TR-10-46

U.S. Army Engineer Research and Development Center

Geotechnical and Structures Laboratory

3909 Halls Ferry Road

Vicksburg, MS 39180-6199

\section{SPONSORING I MONITORING AGENCY NAME(S) AND ADDRESS(ES)}

10. SPONSOR/MONITOR'S ACRONYM(S)

Headquarters, U.S. Army Corps of Engineers

Washington, DC 20314-1000

\section{DISTRIBUTION / AVAILABILITY STATEMENT}

Approved for public release; distribution is unlimited.

\section{SUPPLEMENTARY NOTES}

\section{ABSTRACT}

Through multiple efforts, the U.S. Army Engineer Research and Development Center is conducting developmental research focused on new ultra high-performance cementitious materials. As a part of this research, a particular material, named Cor-Tuf, has been developed. Cor-Tuf is an ultra high-strength concrete, and has been shown to exhibit unconfined compressive strengths as high as $240 \mathrm{MPa}$. Randomly distributed steel reinforcement fibers (30-mm length) have been incorporated into Cor-Tuf to improve its ductility under tensile stresses, although their effect on performance has not been fully quantified. This considered, the research effort described herein was conducted to characterize the tension (splitting tensile) and flexural properties of the Cor-Tuf material. Seven experimental series were performed, and included 33 flexural tests and 12 splitting tensile tests. Testing was conducted utilizing reinforced and unreinforced material in order to directly quantify the fibers' influence on material response. This report provides descriptions of the experimental configurations, test specimens, and a summary of the experimental results.

\section{SUBJECT TERMS \\ Cementitious \\ Cor-Tuf}

\begin{tabular}{|l|l|l|}
\hline \multicolumn{3}{|c|}{} \\
\hline a. REPORT & b. ABSTRACT & c. THIS PAGE \\
UNCLASSIFIED & UNCLASSIFIED & UNCLASSIFIED \\
\hline
\end{tabular}

Flexural tests

Splitting tensile tests

17. LIMITATION
OF ABSTRACT

Ultra high-strength concrete

\begin{tabular}{c|l}
\begin{tabular}{c|c} 
18. NUMBER \\
OF PAGES
\end{tabular} & $\begin{array}{l}\text { 19a. NAME OF RESPONSIBLE } \\
\text { PERSON }\end{array}$ \\
\cline { 2 - 2 } 56 & $\begin{array}{l}\text { 19b. TELEPHONE NUMBER (include } \\
\text { area code) }\end{array}$ \\
&
\end{tabular}

